\title{
On whether azimuthal isotropy and alongshelf translational invariance are present in low-frequency acoustic propagation along the New Jersey shelfbreak
}

\author{
James F. Lyncha) \\ Applied Ocean Physics and Engineering Department, Woods Hole Oceanographic Institution, \\ 266 Woods Hole Road, Woods Hole, Massachusetts 02543 \\ Chris Emerson and Philip A. Abbot \\ Ocean Acoustical Services and Instrumentation Systems, Inc., 5 Militia Drive, Lexington, Massachusetts 02421 \\ Glen G. Gawarkiewicz \\ Physical Oceanography Department, Woods Hole Oceanographic Institution, 266 Woods Hole Road, \\ Woods Hole, Massachusetts 02543 \\ Arthur E. Newhall, Ying-Tsong Lin, and Timothy F. Duda \\ Applied Ocean Physics and Engineering Department, Woods Hole Oceanographic Institution, \\ 266 Woods Hole Road, Woods Hole, Massachusetts 02543
}

(Received 10 May 2011; revised 1 December 2011; accepted 1 December 2011)

\begin{abstract}
To understand the issues associated with the presence (or lack) of azimuthal isotropy and horizontal (along isobath) invariance of low-frequency (center frequencies of $600 \mathrm{~Hz}$ and $900 \mathrm{~Hz}$ ) acoustic propagation in a shelfbreak environment, a series of experiments were conducted under the Autonomous Wide-Aperture Cluster for Surveillance component of the Shallow Water 2006 experiment. Transmission loss data reported here were from two mobile acoustic sources executing (nearly) circular tracks transmitting to sonobuoy receivers in the circle centers, and from one $12.5 \mathrm{~km}$ alongshelf acoustic track. The circle radii were $7.5 \mathrm{~km}$. Data are from September 8, 2006. Details of the acoustic and environmental measurements are presented. Simple analytic and computer models are used to assess the variability expected due to the ocean and seabed conditions encountered. A comparison of model results and data is made, which shows preliminary consistency between the data and the models, but also points towards further work that should be undertaken specifically in enlarging the range and frequency parameter space, and in looking at integrated transmission loss. (C) 2012 Acoustical Society of America. [DOI: 10.1121/1.3672644]
\end{abstract}

PACS number(s): 43.30.Dr, 43.20.El, 43.20.Fn, 43.30.Re [JAC]

Pages: $1762-1781$

\section{BACKGROUND/INTRODUCTION}

In order to understand the issues associated with the presence (or lack) of azimuthal isotropy and horizontal (along isobath) invariance of low-frequency $(600 \mathrm{~Hz}$ and $900 \mathrm{~Hz}$ center frequencies) acoustic propagation in a shelfbreak environment, a series of experiments were conducted under the Autonomous Wide-Aperture Cluster for Surveillance (AWACS) component of the Shallow Water 2006 (SW06) experiment conducted directly off the New Jersey, USA coast [Fig. 1(a)]. Data are reported here from September 8,2006 , when two simultaneous (nearly) circular tracks were followed by two mobile acoustic sources that were transmitting to drifting sonobuoy receivers near the circle centers. These tracks, shown in Figs. 1(b) and 1(c), provide highly resolved angular measurements of the azimuthal dependence of acoustic propagation, as well as multitransmission measurements that can determine the extent of horizontal variability (or lack thereof) along the shelf. A separate alongshelf acoustic track is also reported on.

\footnotetext{
a) Author to whom correspondence should be addressed. Electronic mail: jlynch@whoi.edu
}

Environmentally, this experiment was conducted in a complex area-the continental shelfbreak region of the MidAtlantic Bight. Oceanographically, this region features a strong shelfbreak front, a nonlinear internal wave field, eddies and filaments radiated from the Gulf Stream, and the usual complement of surface waves, all of which can have significant acoustic effects (Tang et al., 2007). Geologically and geo-acoustically, the region is characterized by sloping and irregular bathymetry due to the shelfbreak and the canyons that cross-cut it, and by bottom material that can have significant stratigraphic and material variation in both the along and across shelf directions (Ballard et al., 2010). Biologically, Diachok et al. (2004) and Makris et al. (2006) have shown that fish schooling near the front can lead to significant attenuation at the two acoustic frequencies that we will be considering. Moreover, although the sampling resources in this experiment exceeded those of many experiments, our sampling, and thus the resolution of the oceanography, geology/geophysics, and biology, is limited (as always) by finite measurement resources.

This paper is structured as follows. Following this introduction, the large scale ocean-acoustic environment is examined. (The finer scale oceanography, geology, biology, etc. 


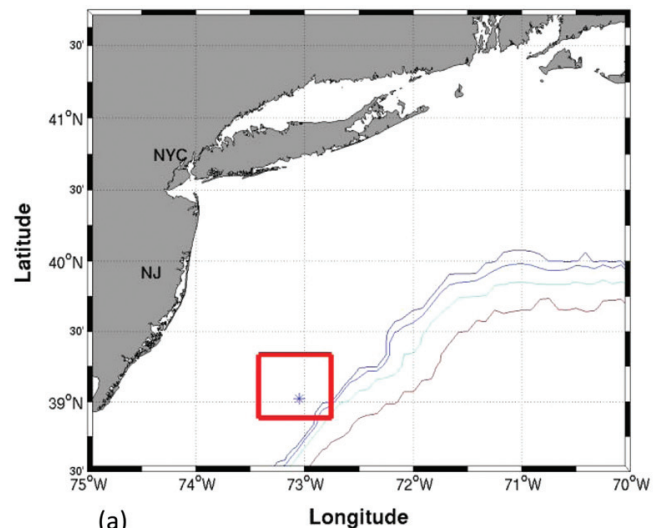

(a)
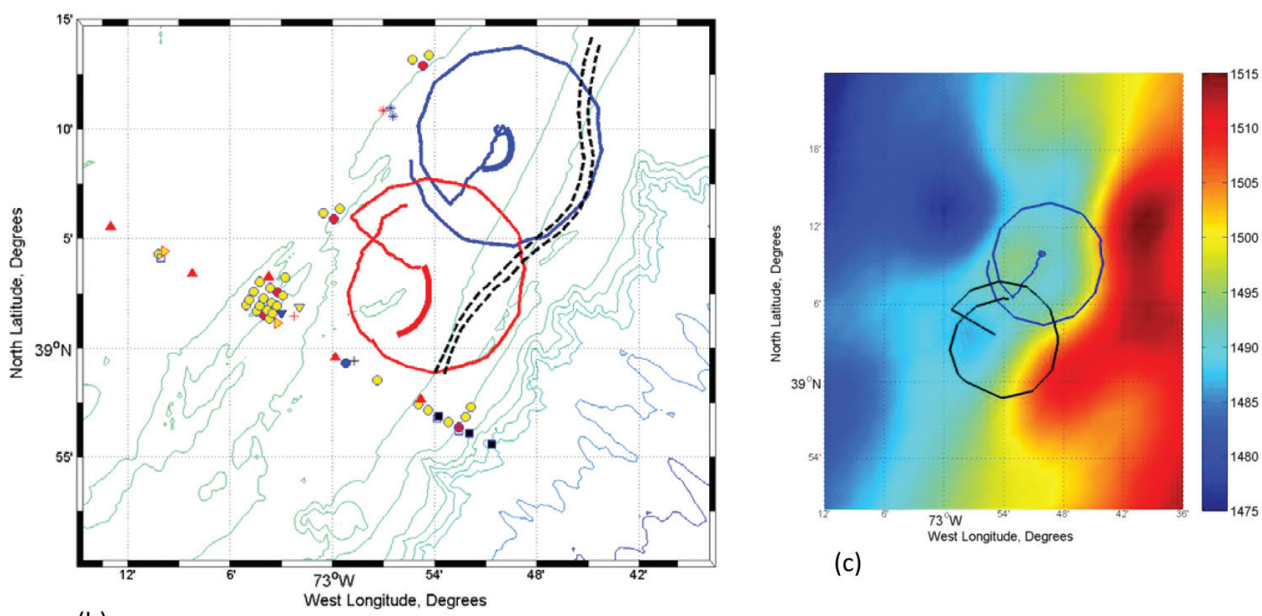

(c)
FIG. 1. Panel (a) SW06 area east of New Jersey, USA. Panel (b): Positions of Mobile Acoustic Source (OMAS) vehicles (thinner blue [OMAS1] and red [OMAS2] lines) and sonobuoy receivers (thicker red and blue lines) for September 8, 2006 transmissions during SW06. Position of the shelfbreak front, as determined by a Scanfish towed conductivity-temperature-depth (CTD) survey, is shown by the black dashed line. Positions of SW06 oceanographic and acoustic moorings are shown by colored circles, triangles, and squares for reference. Panel (c): Reconstruction of the two OMAS tracks overlaid on an objective map of sound speed at the vehicle operating depth $(40 \mathrm{~m})$. Note that both vehicles operated in generally horizontally isovelocity $(\mathrm{c} \cong 1490 \mathrm{~m} / \mathrm{s})$ sound speed conditions except when they passed through the shelfbreak front (indicated by a rapid increase in sound speed from west to east) at true bearings from approximately $060^{\circ}$ to $180^{\circ}$. Also note that the radius of each circle was about $7.5 \mathrm{~km}$ and the distance between circle centers was about $12.5 \mathrm{~km}$. will be described in the subsequent modeling sections of the paper.) Next, the acoustic experiment is described in detail, e.g., the geometry, the acoustic signals transmitted, the processing and analyses done, etc. Following this, the acoustic data are examined, with emphasis on the mean and variance of the received field, and on the spatial (azimuthal, as well as translational) dependence of these results. In doing this, we draw on the work presented in Abbot et al. (2006b), one of the first attempts to evaluate the isotropy (or lack thereof) of an azimuthally distributed, shallow-water transmission loss (TL) data set. Next, detailed modeling of the data is presented, with the aim being to explain the major features of the data that reflect on azimuthal and translational invariance of the transmission loss. Finally, the results and conclusions of the paper are discussed.

\section{LARGE SCALE OCEANOGRAPHIC SETTING AND VARIABILITY}

The experiment was conducted over the outer continental shelf and upper continental slope [Fig. 1(a)] in the vicinity of the shelfbreak front. This front divides the relatively cool and fresh waters of the continental shelf from the warm and saline waters of the continental slope. The climatological structure of the front has been described in Linder and Gawarkiewicz (1998) and Linder et al. (2006). During the experiment, the frontal structure was strongly affected by two external forcing factors: a warm core ring directly adjacent to the front during the first leg of the cruise (August 24-31) and Tropical Storm Ernesto, which passed through the study area on September 1 and 2 and substantially changed the stratification throughout the study region.

The R/V Endeavor sampled the mesoscale oceanography in the area in order to resolve the position and structure of the shelfbreak front on daily time scales. The sampling was designed to resolve the spatial (order $10 \mathrm{~km}$ ) and temporal (order one day) decorrelation scales associated with the front (Gawarkiewicz et al., 2004). The primary tool for hydrographic sampling was the towed Scanfish vehicle, which contained a SeaBird 911+ CTD along with fluorometer, transmissometer, and oxygen sensors. The towed Scanfish undulated between a depth of $2 \mathrm{~m}$ and $120 \mathrm{~m}$ or within $3 \mathrm{~m}$ of the bottom.

Because of concurrent oceanographic sampling of the shelfbreak front and acoustic sampling of low-frequency acoustic propagation using the mobile acoustic sources and sonobuoys, it was necessary to develop a strategy to choose acoustic transmission paths that related to the oceanographic parameters. The known variability of the front and the small time and space decorrelation scales were expected to strongly impact the transmission loss and acoustic propagation, and thus were necessary to resolve with the hydrographic sampling.

To guide both the oceanographic and acoustic sampling, we thus designed the hydrographic sampling to focus on resolving the following: 


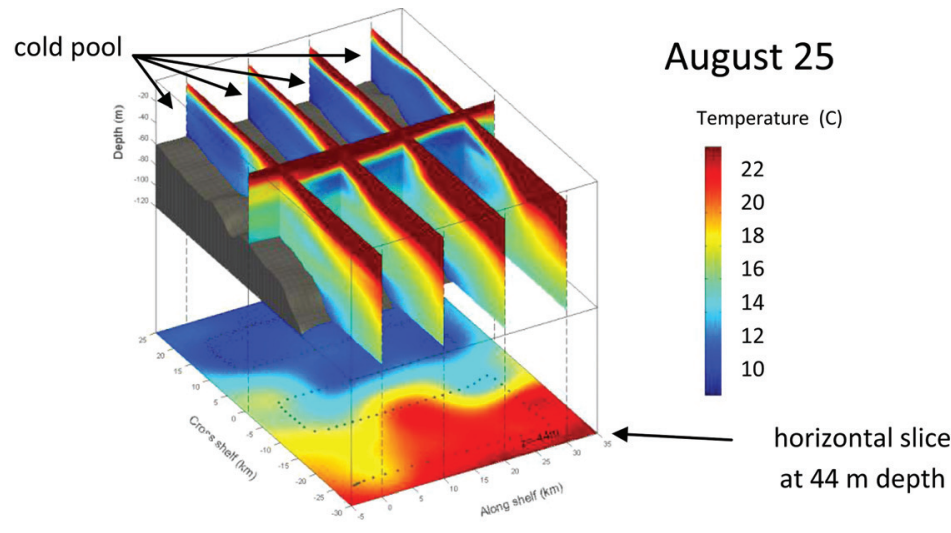

(a)

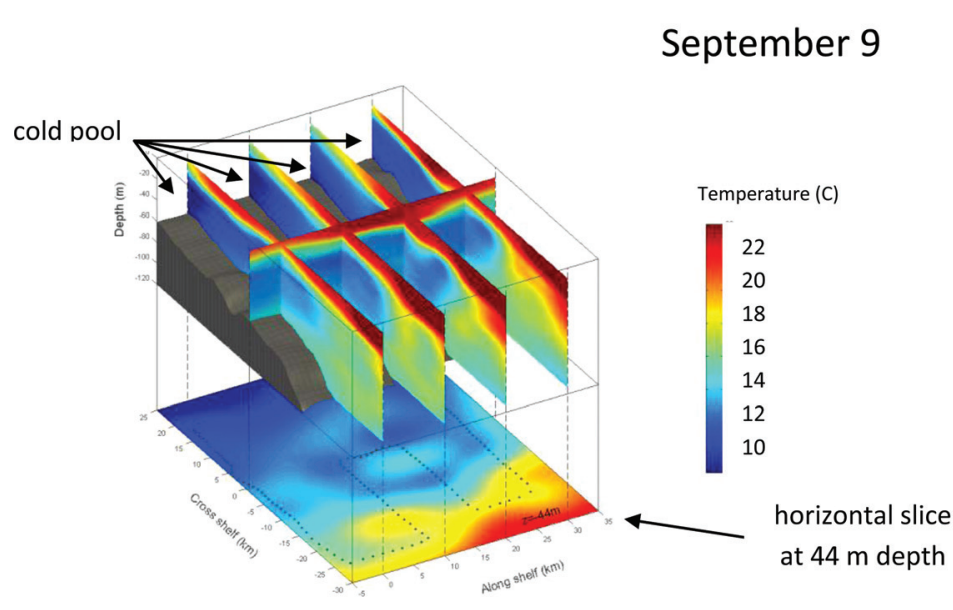

(c)
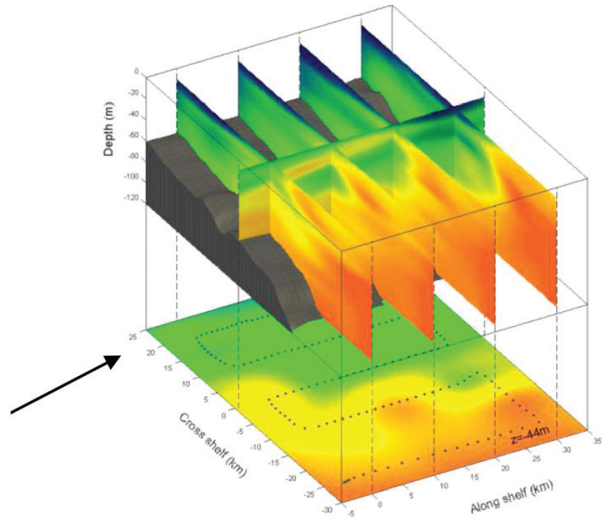

Salinity (psu)
36
35
34
33
32
31

(b)
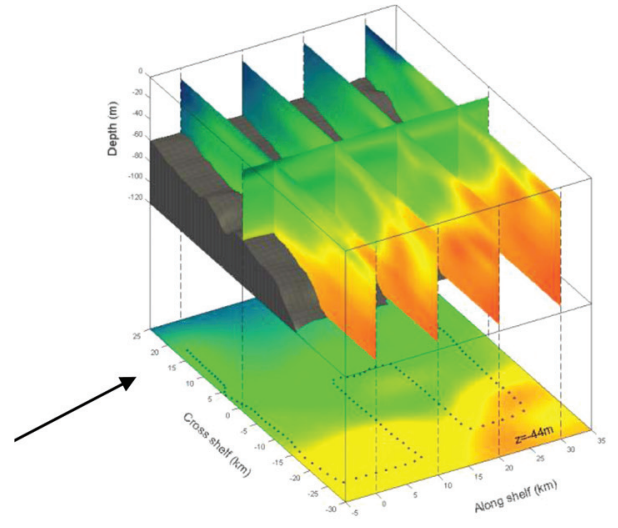

(d)

FIG. 2. Panels (a) and (b): A visualization of the (a) temperature and (b) salinity fields from August 25, 2006. The sections which appear are based on objective mapping of the multiple (along-isobath) transects using the towed Scanfish. At the bottom of the 3D slices are the temperature and salinity at $44 \mathrm{~m}$ depth to show the cross-shelf structure more clearly. The shoreward displacement of the front by the warm core ring is clearly seen in the $44 \mathrm{~m}$ slice. Panels (c) and (d) show: the (c) temperature and (d) salinity fields from September 9, 2006. Again, the bottom of the 3D slices indicates the fields at a depth of 44 m. In both cases the sampling was done with a cross-shelf orientation and with objectively mapped fields.

(1) the cross-shelf position of the maximum cross-shelf temperature gradients at $40 \mathrm{~m}$ depth (the nominal cross-shelf position of the shelfbreak front).

(2) the depth of the temperature minimum within the water column (axis of the "Cold Pool Duct" (Houghton et al., 1982), which is due to the remnant of convectively cooled water from the previous winter).

(3) the surface mixed layer depth, and

(4) the cross-shelf position of the maximum cross-shelf temperature gradient along the bottom (cross-shelf position of the foot of the shelfbreak front).

During the period before Tropical Storm Ernesto, which interrupted operations from September 1 to September 3, the shelfbreak front was strongly affected by a warm core ring present adjacent to the front. This can be seen in both the temperature and salinity fields from August 25, shown in Figs. 2(a) and 2(b). The depth of the seasonal pycnocline was roughly $40 \mathrm{~m}$ in areas over the upper continental slope and $15 \mathrm{~m}$ in areas over the continental shelf. As a result of the close proximity of the warm core ring, the frontal position was well shoreward of the climatological mean position, as is seen in the $44 \mathrm{~m}$ horizontal slice. Associated with the warm core ring were saline intrusions which were concentrated at approximately $20 \mathrm{~m}$ depth, near the depth of peak stratification found over the continental shelf, consistent with the prior results of Lentz (2003). These intrusions have been identified as a common summer shelf-slope exchange process (e.g., Boicourt and Hacker, 1976; Gordon and Aikman, 1981; Aikman, 1984; Burrage and Garvine, 1988; Gawarkiewicz et al., 1990; Flagg et al., 1994; Churchill et al., 2003). The along-shelf scale of the saline intrusions was $\sim 20 \mathrm{~km}$ and the intrusions were associated with weakened peak stratifications relative to the mean stratification over the continental shelf. Associated with the saline intrusion was a large amplitude frontal meander, similar to that observed by Gawarkiewicz et al. (2004), which propagated through the study area to the southwest at a speed of roughly $10 \mathrm{~cm} / \mathrm{s}$. Both the saline intrusions and the associated frontal meander will be addressed in more detail in a future study. 
After Tropical Storm Ernesto, with peak wind speeds of over $20 \mathrm{~m} / \mathrm{s}$, there were a number of changes to the shelfbreak frontal structure, shown in Figs. 2(c) and 2(d). There was substantial mixing both above and below the seasonal pycnocline and a slight deepening of the pycnocline to a depth of $25 \mathrm{~m}$. The shelfbreak frontal position (maximum cross-shelf temperature gradient at $40 \mathrm{~m}$ depth) shifted offshore by $15 \mathrm{~km}$ and the foot of the shelfbreak front moved from the $80 \mathrm{~m}$ isobath to the $100 \mathrm{~m}$ isobath after the passage of the tropical storm. There were also saline intrusions which began to form but they did not penetrate onshore very far, in contrast to the fully developed saline intrusions prior to the storm. An objective map of soundspeed variability observed by the Scanfish survey on September 8 is superimposed with the mobile acoustic source tracks which are shown in Fig. 1(c).

The sampling strategy was successful in resolving the shelfbreak frontal structure and position. The frontal position was resolved to within $1 \mathrm{~km}$ accuracy during the transects. Examination of the error fields from objective maps show errors that are less than 20 percent of the total variance field within the grids sampled by the Scanfish vehicle. For some transects with larger spacing, errors occasionally rose to 30 percent of the total variance field. For positions close to the transects errors were less than ten percent of the total variance field. One should note that the objective maps do not resolve tidal motions of the front over the time period of the sampling (generally $12 \mathrm{hrs}$ ), which adds to the uncertainty in frontal position at a specific moment in time. However, the tidal excursions within the front were much smaller than cross-shelf excursions due to frontal meandering and shoreward excursion due to the presence of the warm core ring.

As mentioned previously, the intent of the hydrographic surveys was to resolve the front for propagation modeling but also to drive the adaptive sampling for acoustic propagation. Over the course of the experiment, a number of crossings of the shelfbreak front, as well as the saline intrusions over the continental shelf, were made to investigate the effects of these frontal features and the associated internal wave field on acoustic propagation.

\section{ACOUSTIC EXPERIMENTAL DETAILS}

\section{A. Mobile acoustic source description}

The OASIS Mobile Acoustic Source (OMAS) used in SW06 is a small, low cost, expendable unmanned underwater vehicle (UUV) equipped with a broadband acoustic source that has been developed for in situ transmission loss (TL) and other acoustic measurements (Abbot et al., 2006a). The vehicle is $12.4 \mathrm{~cm}$ in diameter, $91.4 \mathrm{~cm}$ long and weighs $10 \mathrm{~kg}$.

The OMAS is tracked in real-time by means of timesynchronizing the source with at least two hydrophone receivers, which enables the calculation of source range from the measured time delay between signal transmission and reception. On a ping-by-ping basis (once per minute), the received hyperbolic frequency modulated (HFM) signals are matched-filter processed and then the source range and TL are measured, along with bearing (via use of the directional sonobuoys). Triangulation methods are used to obtain the actual vehicle track.

Two vehicles were used on September 8, with identical (vehicle to vehicle) source levels for the hyperbolic frequency modulated (HFM) chirps at both $600 \mathrm{~Hz}$ and $900 \mathrm{~Hz}$, namely $144.2 \mathrm{~dB} / / 1 \mu \mathrm{Pa} @ 1 \mathrm{~m}$ and $149.0 \mathrm{~dB} / / 1 \mu \mathrm{Pa} @ 1 \mathrm{~m}$, respectively. Ping-to-ping variability for each unit is small $(<0.25 \mathrm{~dB})$, and source level sensitivity to the vehicle battery load over time is less than $0.5 \mathrm{~dB}$ over a four-hour test cycle. Also for these operations, each vehicle's speed was set to five knots which allowed for at least seven hours of vehicle life.

\section{B. SW06 OMAS Operations, 9/08/2006}

During the September 8 SW06 OMAS operations, the two OMAS source vehicles performed simultaneous circular tracks (of radius $7.5 \mathrm{~km}$ ) around sonobuoy receivers which were separated by approximately $15 \mathrm{~km}$. The vehicles transmitted similar, but frequency separated, acoustic signals. The actual tracks of the OMAS and sonobuoy (drift) are shown in Fig. 1(b).

The first vehicle transmitted three two-second $800-1000 \mathrm{~Hz}$ HFM upsweeps followed by three two-second $550-650 \mathrm{~Hz}$ HFM upsweeps, followed by 48 seconds of continuous waves (CWs) at $800 \mathrm{~Hz}, 900 \mathrm{~Hz}$ and $1000 \mathrm{~Hz}$ (all with source levels $140 \mathrm{~dB} / / 1 \mu \mathrm{Pa} @ 1 \mathrm{~m})$. The entire transmission sequence was one minute in duration and repeated every minute. To have the vehicles simultaneously transmit at roughly the same bearings relative to the receivers at their respective circle's center, this vehicle loitered near the launch position for 16 minutes and then traveled at a magnetic heading of $223^{\circ}$ for 48 minutes, covering a total of approximately $7.4 \mathrm{~km}$. After arriving at the desired position, it then began a clockwise circular track (approximated by twelve linear segments), traveling at $2.6 \mathrm{~m} / \mathrm{s}$ (five knots) at a depth of $40 \mathrm{~m}$.

The second vehicle transmitted signals identical to the first vehicle except that downsweeps were used and all $\mathrm{CW}$ frequencies were reduced by $20 \mathrm{~Hz}$ to help differentiate between vehicles. Upon launch, the second vehicle immediately traveled at a magnetic heading of $313^{\circ}$ for 48 minutes, covering a total of approximately $7.4 \mathrm{~km}$, and then began the same clockwise circular track (same depth, speed) as described for the first vehicle. Note that, for both vehicles, a speed of five knots $(2.6 \mathrm{~m} / \mathrm{s})$ at a range of $7.5 \mathrm{~km}$ implies a bearing rate of 1.2 degree/min.

The first sonobuoy receiver was an omnidirectional hydrophone (referred to as OMNI1). This receiver was set to operate at $61 \mathrm{~m}$ depth and was tethered $(<10 \mathrm{~m})$ to a spar buoy equipped with a global positioning system (GPS) receiver and data logger that was used in postprocessing to reconstruct the buoy location. This buoy was deployed at $39^{\circ} 10.221^{\prime} \mathrm{N}, 72^{\circ} 49.981^{\prime} \mathrm{W}$ (see Fig. 1) at time $12: 35(\mathrm{Z})$ on September 8 th. The second sonobuoy receiver was also an omnidirectional hydrophone (referred to as OMNI2). It also was set to operate at $61 \mathrm{~m}$ depth and similarly tethered to a 
OMAS 1
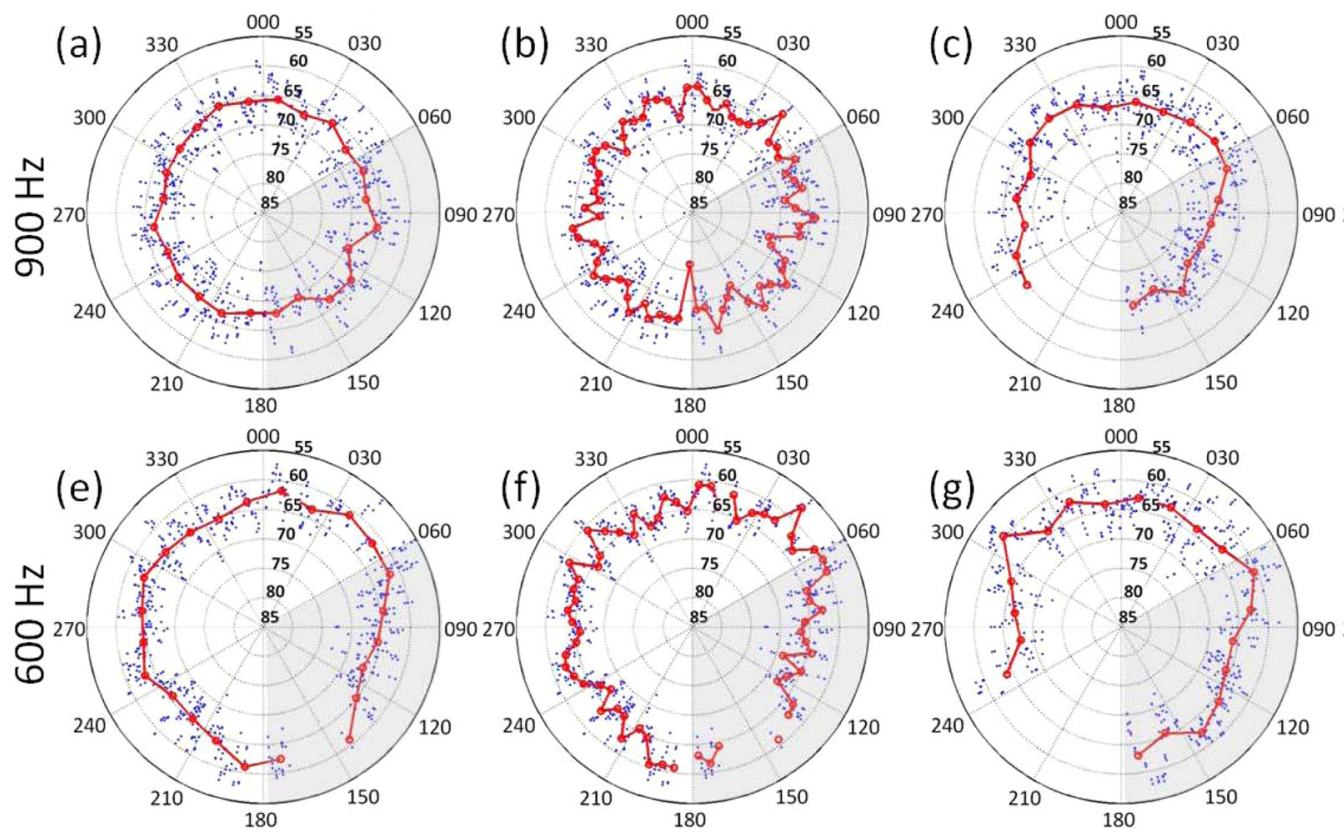

OMAS 2
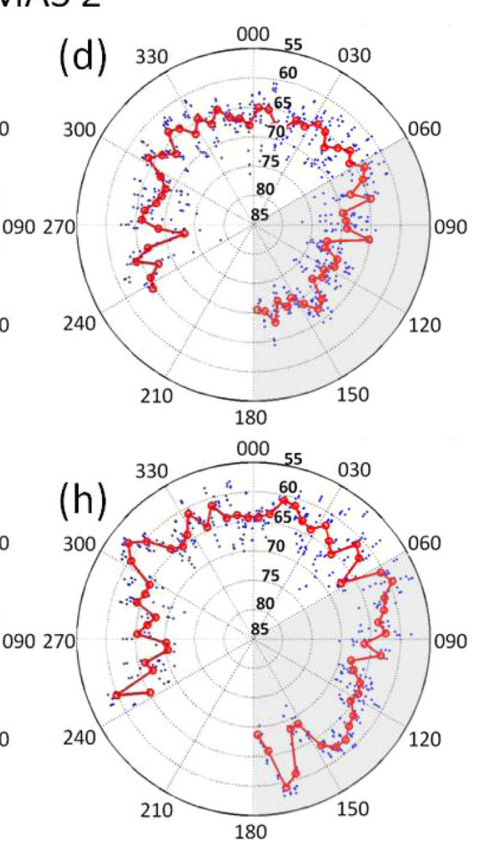

FIG. 3. (Color online) Azimuthal TL (dB re $1 \mathrm{~m}$ ) variability measured from the OMAS operation on September 8 th, 2006 during the SW06 experiment. Data at two frequencies $(900 \mathrm{~Hz}$ in the top row, panels (a)-(d), and $600 \mathrm{~Hz}$ in the bottom row, panels (e)-(h) from two different OMAS vehicles (OMAS1 on the left side, panels (a), (b), (e) and (f) and OMAS2 on the right side, panels (c), (d), (g) and (h) are shown. Two different azimuthal average apertures (15 ${ }^{\circ}$ in panels (a), (c), (e) and (g), and $5^{\circ}$ in panels (b), (d), (f) and (h) are applied. The raw data are shown as small dots, and the average values are shown as lines with circular markers showing the individual mean TL data points. The shaded portion of the plots indicates the approximate bearings at which the source is considered to be in the shelfbreak front. All source and receiver depths are $40 \mathrm{~m}$ and $61 \mathrm{~m}$, respectively.

GPS-equipped spar buoy, was deployed at $39^{\circ} 3.763^{\prime} \mathrm{N}$, $-72^{\circ} 54.669^{\prime} \mathrm{W}$ (see Fig. 1) at time 13:28(Z). The OMAS1 vehicle was deployed near the OMNI1 spar buoy at 12:41(Z) and the OMAS2 vehicle was deployed near the OMNI2 spar buoy at 13:36(Z).

The received signals are first matched-filtered, and then TL is calculated for each $(600 \mathrm{~Hz}$ and $900 \mathrm{~Hz})$ HFM sweep as the difference between the peak of the matched filter output with at least $6 \mathrm{~dB}$ signal to noise ratio (SNR) and the known source level. There is a disadvantage to this method in that it does not consider all the multipath propagation energy. On the other hand, it also does not include any of the noise that invariably creeps into any integration window, causing error in the resulting integrated TL values to a degree that is inversely proportional to the signal-to-noise ratio (SNR). The TL measurements are detailed further in the next section.

In order to plot TL behavior versus bearing, the TL data are first corrected to a common range of $7.5 \mathrm{~km}$, via a $15 \log (\mathrm{R})$ spreading loss correction (the range dependence of the TL was determined from data collected during the each vehicle's initial linear track from its deployment position at the circle center out to the circle perimeter). The mean of the actual OMAS1 ranges (distorted from a perfect $7.5 \mathrm{~km}$ circle by vehicle and receiver drift) was $7.8 \mathrm{~km}$, with variations between a minimum of $7.1 \mathrm{~km}$ and a maximum of $8.6 \mathrm{~km}$, resulting in maximum TL range corrections of $0.9 \mathrm{~dB}$. The mean of the actual OMAS2 ranges was $7.6 \mathrm{~km}$, with variations between a minimum of $4.8 \mathrm{~km}$ and a maximum of $9.3 \mathrm{~km}$, resulting in slightly higher corrections of up to $2.9 \mathrm{~dB}$.

\section{ACOUSTIC OBSERVATIONS}

\section{A. Overview of the acoustic data}

The resulting azimuthal TL measurements, corrected to $7.5 \mathrm{~km}$ range, are shown in Fig. 3. Focusing first on the $900 \mathrm{~Hz}$ transmissions from OMAS1 to OMNI1, shown in Figs. 3(a) and 3(b), individual TL data points are plotted on a ping-by-ping basis versus azimuthal angle (from source to receiver) $\varphi$ as dots. Upon first look, the individual data points fluctuate in azimuth and can vary up to $15 \mathrm{~dB}$ with small changes in $\varphi$. This ping-to-ping variability makes it difficult to determine what these data reveal about the azimuth dependence or translational invariance of the TL. Thus, some level of averaging in azimuth becomes necessary. We start by binning the individual TL data points in both $15^{\circ}$ and $5^{\circ}$ sectors, then average the logs of the binned data. This smoothing has the effect of reducing the underlying stochastic fluctuations in the TL at the cost of a reduction of the resolution in bearing. Figure 3(a) shows the $15^{\circ}$ sector averages as a solid line with circular markers denoting the mean value of the individual measured TL in each sector. Figure 3(b) shows the corresponding $5^{\circ}$ sector averages of the same raw data. Figures 3(c) and 3(d) show the same averaging of the $900 \mathrm{~Hz}$ TL for transmissions from OMAS2 to OMNI2, while Figs. 3(e) through 3(h) show the same averaging applied to the $600 \mathrm{~Hz}$ TL data for both vehicles in the same order used above.

The $15^{\circ}$ sector-averaging of the TL shown in Figs. 3(a), 3(c), 3(e), and 3(g), smoothes through the variability of the individual data points, providing robust estimates of the mean TL over all bearings. Fifteen degree sector averaging 


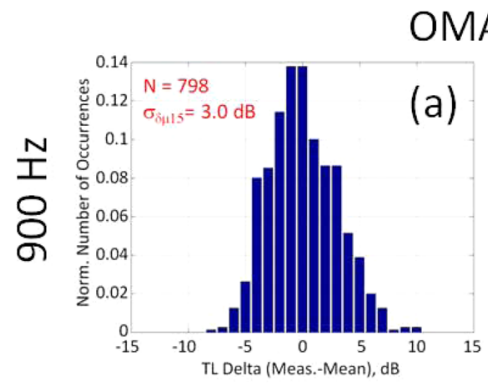

MAS 1
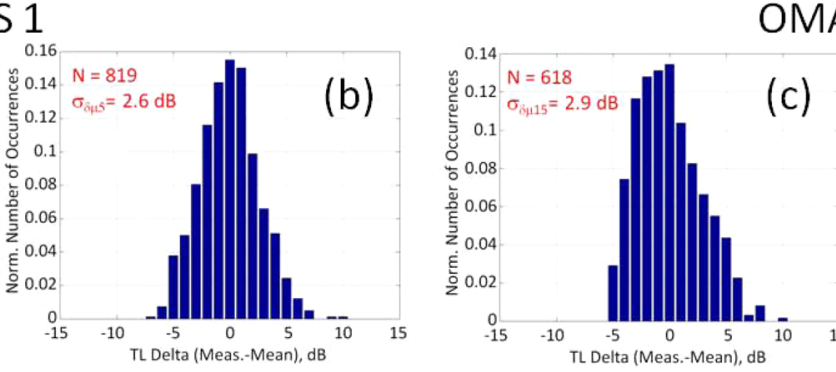

OMAS 2
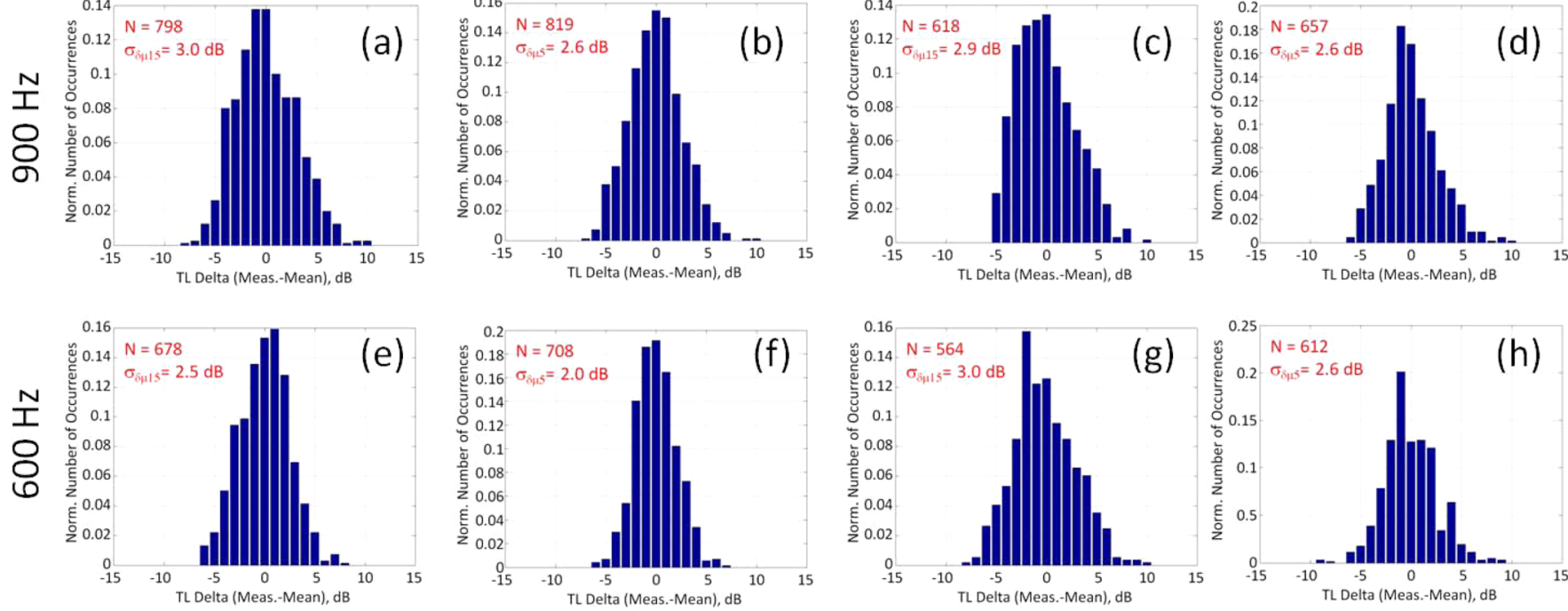

FIG. 4. (Color online) Histograms of the differences between the individual measured TL data points (small points in Fig. 3 ) and the azimuthal means (15 and $5^{\circ}$, shown by lines in Fig. 3). The figures are ordered as in Fig. 3. Each figure has the number of TL measurement samples (N) and the corresponding standard deviations $\left(\sigma_{\delta \mu}\right)$ given.

at both frequencies appear qualitatively isotropic, with slightly more variability over bearing (less isotropy) in the $600 \mathrm{~Hz}$ case than in the $900 \mathrm{~Hz}$ case. The $15^{\circ}$ means also appear to be similar at the two locations (translationally invariant), again, more so at $900 \mathrm{~Hz}$ than at $600 \mathrm{~Hz}$. The $5^{\circ}$ sector-averaged TL results, shown in Fig. 3(b), 3(d), 3(f), and $3(\mathrm{~h})$, preserve much of the finescale variability seen in the individual TL data points, generally varying within a $10 \mathrm{~dB}$ envelope at both frequencies and locations. The case for isotropy is clearly weakened with the narrower binning, and conclusions as to translational invariance are difficult without a direct comparison of the results for the two vehicles (which will be included below). With these qualitative results in mind, further work (described in Sec. IV-B) seeks to develop quantitative rules of thumb for assessing both isotropy and translational invariance.

Before moving on to discussions of isotropy and invariance, however, we first examine the fluctuations of the individual TL data points about the $15^{\circ}$ and $5^{\circ}$ sector averages. Histograms of these differences are presented in Fig. 4 in the same order used in Fig. 3. Each histogram indicates the number of TL samples $(\mathrm{N})$ represented as well as the standard deviation $\left(\sigma_{\delta \mu}\right)$ of these TL differences relative to their respective means. In addition to a predictable reduction in variability with a smaller bin width, there is a clear trend to the $900 \mathrm{~Hz} \sigma_{\delta \mu}$ data shown in the top half of the figure, with $\sigma_{\delta \mu 15}$ equal to $3.0 \mathrm{~dB}$, and $\sigma_{\delta \mu 5}$ equal to $2.6 \mathrm{~dB}$ for both vehicles. Although there is no reason to expect the $600 \mathrm{~Hz}$ data to agree with the $900 \mathrm{~Hz}$ data, due to its smaller timebandwidth product, the OMAS2 $600 \mathrm{~Hz}$ results are, in fact, consistent with the $900 \mathrm{~Hz}$ data. The OMAS1 $600 \mathrm{~Hz}$ data departs from this, with a $\sigma_{\delta \mu 15}$ of $2.5 \mathrm{~dB}$ and a $\sigma_{\delta \mu 5}$ of $2.0 \mathrm{~dB}$ [We use standard deviation a as a measure of the variability of the data about the given means, as discussed in Abbot et al. (2006b)].

It should also be noted that while all TL data plotted versus bearing in Fig. 3 are included in the data sets used to produce the histograms in Fig. 4, further study (to be detailed later in this paper) suggests that there are two different TL regimes present. The first regime includes data collected while the source vehicle was in the more oceanographically variable waters of the shelfbreak front $\left(60^{\circ}<\varphi<180^{\circ}\right)$. The second regime includes data collected while the source vehicle was in the more isotropic waters shoreward of the shelfbreak front. Table I shows the variability of the TL in the 'shoreward-of-the-front' region.

When doing the binning, it should be stated that there is no a priori reason why we should choose five degrees and fifteen degrees for bin widths, rather than ten or thirty or two, for that matter. We do notice in the panels of Fig. 3 that by picking a larger bin width (in degrees), we smooth the mean (this is shown by the lower standard deviation of the angular sector averages $\left(\sigma_{\mu}\right)$ for the $15^{\circ}$ sector average versus the $5^{\circ}$ sector average in Table I), but increase the

TABLE I. 'Out-of-the-front' ( $\varphi$ from $180^{\circ}$ to $60^{\circ}$, clockwise) TL data mean $(\mu)$ and standard deviation $(\sigma)$ for individual data points, $5^{\circ}$ and $15^{\circ}$ sector averages.

\begin{tabular}{lcccr}
\hline \hline & $900 \mathrm{~Hz}$, OMAS1 & 900 Hz, OMAS2 & 600 Hz, OMAS1 & 600 Hz, OMAS2 \\
\hline$\mu$ of raw data, dB & 66.7 & 66.2 & 63.8 & 63.6 \\
$\sigma$ of raw data, dB & 3.2 & 3.2 & 2.8 & 1.5 \\
$\sigma$ of $15^{\circ}$ mean, $\sigma_{\mu 15}, \mathrm{~dB}$ & 0.8 & 1.2 & 2.1 & 2.5 \\
$\sigma$ of $5^{\circ}$ mean, $\sigma_{\mu 15}, \mathrm{~dB}$ & 2.1 & 1.9 & 2.8 \\
\hline \hline
\end{tabular}


TABLE II. $\sigma$ is calculated directly from the data, and from the square root of the sum of the variances of the sector averages and the differences of the measured data about the average.

\begin{tabular}{lcccc}
\hline \hline & $900 \mathrm{~Hz}, \mathrm{~V} 1$ & $900 \mathrm{~Hz}, \mathrm{~V} 2$ & $600 \mathrm{~Hz}, \mathrm{~V} 1$ & $600 \mathrm{~Hz}, \mathrm{~V} 2$ \\
\hline$\sigma$ of raw data, $\sigma_{\text {raw }}, \mathrm{dB}$ & 3.1 & 3.5 & 2.9 & 3.5 \\
$15^{\circ}, \sqrt{\sigma_{\mu 15}^{2}+\sigma_{\delta \mu 15}^{2}}$ & 3.2 & 3.5 & 3.0 & 3.6 \\
$5^{\circ}, \sqrt{\sigma_{\mu 5}^{2}+\sigma_{\delta \mu 5}^{2}}$ & 3.3 & 3.5 & 3.0 & 3.8 \\
\hline \hline
\end{tabular}

variance about the mean (this is shown by the higher $\sigma_{\delta \mu}$ for the $15^{\circ}$ sector average versus the $5^{\circ}$ sector average in Fig. 4). Conversely, by decreasing the bin width, we can make the mean more variable, but decrease the data variance about the mean. The total variability in the data is fixed, but it can be partitioned into either the mean or the variance about the mean, depending upon the binning we choose. As shown in Beers (1967), this can be expressed mathematically as

$$
\frac{\partial E^{\text {mean }}}{\partial \varphi_{\text {bin }}}+\frac{\partial E^{\text {var }}}{\partial \varphi_{\text {bin }}}=0
$$

where $E$ is the variability in the TL of the data

Table II shows that this conservation of variance holds for this data set. The first row of the table shows $\sigma_{\text {raw }}$, the standard deviation of all the individual TL data points in Fig. 3. The second and third rows of Table II give the square root of the sum of the variances of the sectoraveraged TL $\left(\sigma_{\mu}{ }^{2}\right)$, and the variances of the difference of the TL data about the mean $\left(\sigma_{\delta \mu}{ }^{2}\right)$ for both frequencies and locations. The variances used in the second row are $\sigma_{\mu 15}{ }^{2}$ (the square of the standard deviation of the $15^{\circ}$ sectoraveraged TL seen in Figs. 3(a), 3(c), 3(e), and 3(g), and $\sigma_{\delta \mu 15}{ }^{2}$ (the square of the standard deviation of the differences between the individual data points and the $15^{\circ}$ mean, shown on the histograms in Figs. 4(a), 4(c), 4(e), and 4(g). The third row of Table II gives the same values for the $5^{\circ}$ sector average, again, for both frequencies and circle locations. The agreement between the total calculated variances, regardless of bin-size, shows that the total variance in the data set is indeed conserved.

The "optimal" bin width for the problem at hand should reflect the physical scale of the (larger scale) azimuthal variations, which should be retained in the mean quantities and not averaged out. With this in mind, an ad hoc "optimization" was done by progressively reducing the bin width, eventually down to a $5^{\circ}$ sector. This produced plots that had robust structures on the scale of about $5-10^{\circ}$ width, which looked visually reasonable.

In anticipation of work detailed below, note that both the $5^{\circ}$ and $15^{\circ}$ sector-averages are useful. The finer binning shows the effects that produce fine scale azimuthal variability, which will be seen to be generally unpredictable (random) in nature. The larger binning averages out these fine scale fluctuations, and thus provides a method for comparing (in the mean) the azimuthal and translational invariance of the TL data obtained from the two OMAS circles.

\section{B. Azimuthal isotropy and translational invariance - complete data set}

The original questions asked at the beginning of this paper were whether TL is azimuthally isotropic and/or transitionally invariant alongshelf on the Mid-Atlantic Bight off New Jersey? To examine this question, let us look at the data from two OMAS runs, shown in Fig. 3, in some detail.

First, consider the issue of azimuthal isotropy. Looking at the $15^{\circ}$ bins, effectively averaging over the finescale variability, we see in Table I that, outside of the shelfbreak front, the mean TL versus bearing curves are isotropic, with standard deviation of about $1 \mathrm{~dB}$ in the $900 \mathrm{~Hz}$ case and 1.5 to $2 \mathrm{~dB}$ in the $600 \mathrm{~Hz}$ case. The greater standard deviation at $600 \mathrm{~Hz}$ is a result of the reduced time-bandwidth product of this signal. This isotropy implies that the large scale oceanography and bottom bathymetry are approximately spatially and temporally constant, which is consistent with the data presented in Fig. 3. Within the shelfbreak front, more loss and greater variability is seen in the acoustic paths. This is due to upslope propagation through the frontal region, which is well understood as a lossy and variable ocean acoustic propagation condition.

In contrast, an examination of the $5^{\circ}$ binned features outside of the shelfbreak front shows significant fine scale azimuthal structure, with a standard deviation of about $2 \mathrm{~dB}$ (consistent with anisotropy, see Table I). Thus, on the fine scale, we assert that there is azimuthal anisotropy. Moreover, it is obvious from comparing the $5^{\circ}$ binned plots that this anisotropy is variable from place to place, and from frequency to frequency (and probably time to time, though we do not have that data). It should also be noted that this fine scale variability structure is probably not constant over longer time periods ( $\sim$ hours) due to temporal ocean variability, so it can in some ways be treated effectively as a random variable.

Next, consider the question of the horizontal invariance of TL. To do this, we will compare the $15^{\circ}$ sector averaged TL plots for the $600 \mathrm{~Hz}$ and $900 \mathrm{~Hz}$ frequencies for both OMAS sources (i.e., both circle locations), as shown in the top row of Fig. 5. The $900 \mathrm{~Hz}$ data are shown to the left and the $600 \mathrm{~Hz}$ data are shown to the right. In both figures, OMAS1 data are shown in red and OMAS2 data are shown in blue. The figures show a rather striking agreement between the azimuthal TL curves at the two sites, despite their along-shelf separation of $12.5 \mathrm{~km}$. Moreover, this agreement is observed at both frequencies. To quantify the extent of this agreement, the differences between the two TL mean results, as well as their statistics, are calculated. The results are shown in the top row of Table III with the mean difference shown in the top left of each block and the standard deviation of the differences given in the lower right. The table shows that for the $15^{\circ}$ sector averages, outside of the shelfbreak front area, the mean TL difference between the two locations is only $0.5 \mathrm{~dB}$ for both frequencies, and the standard deviation of the differences are only $1.4 \mathrm{~dB}$ and $2.3 \mathrm{~dB}$, respectively, for $900 \mathrm{~Hz}$ and $600 \mathrm{~Hz}$ (with the increased standard deviation seen at $600 \mathrm{~Hz}$ again attributable to its reduced time-bandwidth). 

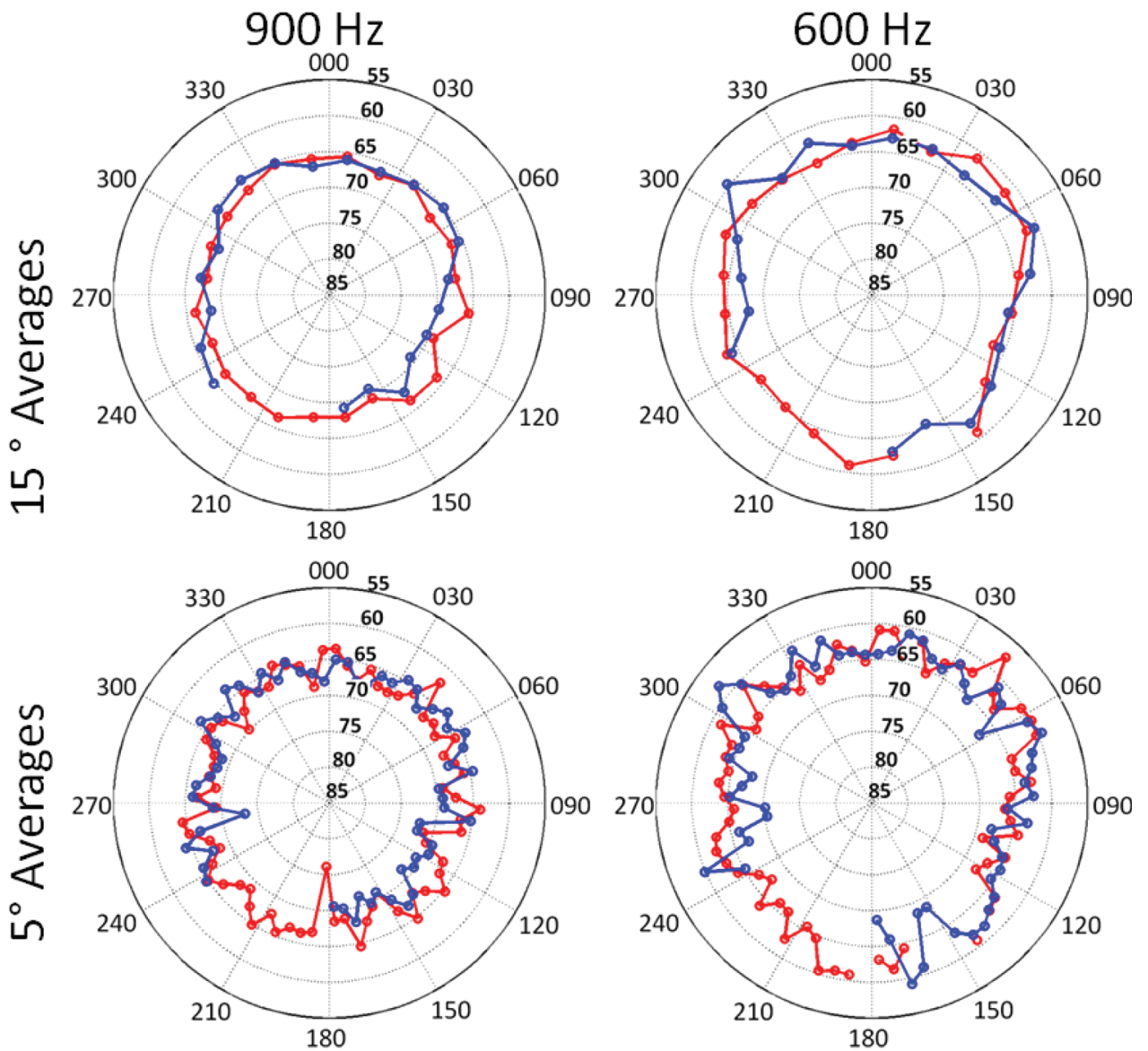

FIG. 5. (a): $15^{\circ} \mathrm{TL}(\mathrm{dB}$ re $1 \mathrm{~m})$ averages of OMAS1 (red) and OMAS2 (blue) at $900 \mathrm{~Hz}$ (left) and $600 \mathrm{~Hz}$ (right). (b): $5^{\circ}$ averages at $900 \mathrm{~Hz}$ (left) and $600 \mathrm{~Hz}$ (right). Again, OMAS1 is shown in red and OMAS2 is shown in blue. (c): Histogram of angular peak widths versus number of occurrences for the combined $600 \mathrm{~Hz}$ and $900 \mathrm{~Hz}$ OMAS runs at the two sites. Though sampled number of peaks is small, there seem to be more occurrences at small angles (less than $15^{\circ}$ ) and at medium angles (around $20^{\circ}-25^{\circ}$ ). More data, and/or fully 3D computer simulations are needed to better

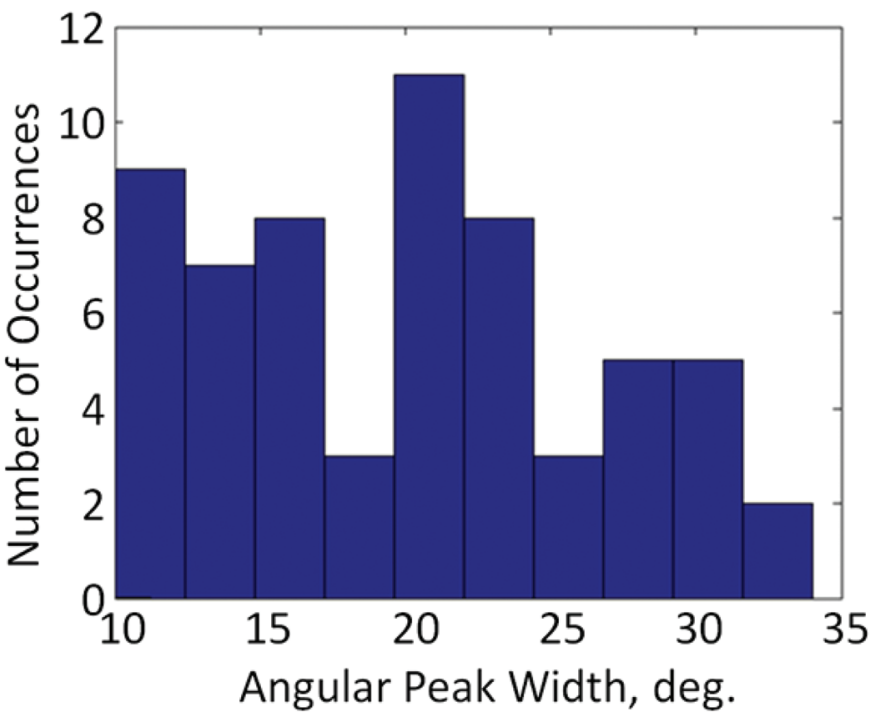
understand the angular widths and their azimuthal positions.

In the middle row of Fig. 5, we show an identical frequency and site comparison for the $5^{\circ}$ sector averaged TL, with the $900 \mathrm{~Hz}$ comparison again shown at the left and the $600 \mathrm{~Hz}$ comparison shown at the right. While the figures show that there is certainly good agreement at some bearings, there are also several bearings that exhibit differences

TABLE III. Translational invariance: mean and standard deviation of differences Between OMAS1 and OMAS2 (OMAS1-OMAS2) $5^{\circ}$ and $15^{\circ}$ mean TL vs bearing for $900 \mathrm{~Hz}$ and $600 \mathrm{~Hz}$, for out-of-the-front data.

\begin{tabular}{lcr}
\hline \hline & $900 \mathrm{~Hz}$ & $600 \mathrm{~Hz}$ \\
\hline $\begin{array}{l}\text { Mean/standard deviation of the difference (OMAS1 } \\
- \text { OMAS2) of } 15^{\circ} \text { mean, Out-of-the-Front, dB }\end{array}$ & $0.5 / 1.4$ & $0.5 / 2.3$ \\
$\begin{array}{l}\text { Mean/standard deviation of the difference (OMAS1 } \\
\text { - OMAS2) of } 5^{\circ} \text { mean, Out-of-the-Front, dB }\end{array}$ & $0.2 / 2.5$ & $0.6 / 3.3$ \\
\hline \hline
\end{tabular}




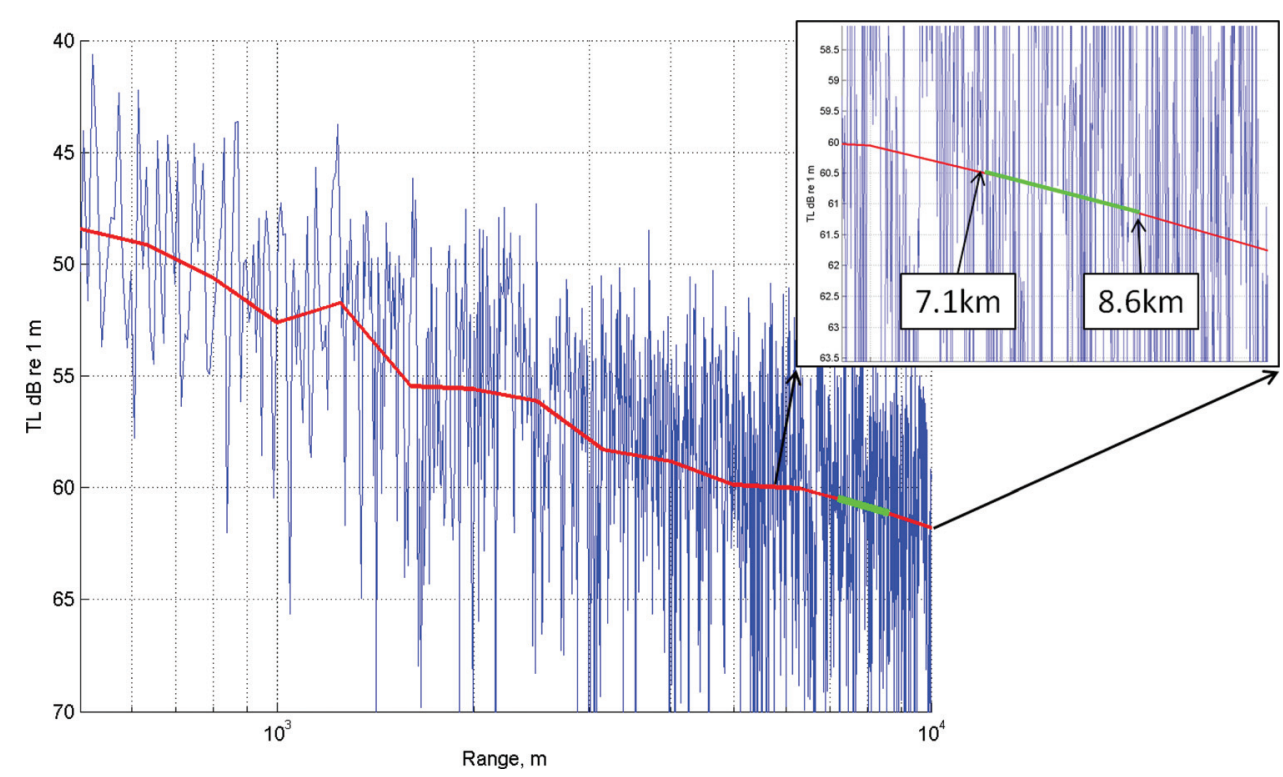

FIG. 6. Modeled $900 \mathrm{~Hz}$ TL vs range in the region of OMAS1. The fluctuations are large for $900 \mathrm{~Hz}$ CW transmissions (blue), but fluctuations are greatly reduced in the $200 \mathrm{~Hz}$ broadband averaged TL (shown in red). The green line shows the broadband averaged TL from 7.1 to $8.6 \mathrm{~km}$, the range variation of OMAS1.

between the two sites of up to $6 \mathrm{~dB}$. Quantifying the degree of the translational invariance as we did above, the results in Table III show that while the mean differences are still low, at $0.2 \mathrm{~dB}$ and $0.6 \mathrm{~dB}$, respectively, for $900 \mathrm{~Hz}$ and $600 \mathrm{~Hz}$, the standard deviation of the differences has risen to $2.5 \mathrm{~dB}$ and $3.3 \mathrm{~dB}$, respectively. From these results we conclude that the $15^{\circ}$ sector-averaged TL outside of the shelfbreak front is both isotropic and translationally invariant over a $12.5 \mathrm{~km}$ along-shelf separation. This isotropy and invariance breaks down when the TL data are averaged in finer $5^{\circ} \mathrm{sec}-$ tors. Potential causes for this breakdown will be discussed in the next section.

Finally, the probability density function (PDF) of peak widths for the $5^{\circ}$ binning is shown in the bottom panel of Fig. 5. The distribution of peak widths is one of the robust observables that we can measure and compare against theoretical predictions.

\section{AZIMUTHAL FINESCALE VARIABILITY - WHAT CAUSES IT?}

In trying to understand how experimental azimuthal finescale TL variability can occur, we identify at least three mechanisms that are germane to our experiment. First, there is circle distortion caused by current effects on the OMAS, our piecewise linear approximation of a circle necessary for OMAS programming purposes, and the drift of the sonobuoy receivers due to both winds and currents. These effects introduce some range-dependence into the TL data. Second, even if one was looking at a perfectly circular track, a rangedependent acoustic waveguide (known to be present in our case, particularly across shelf), would produce additional variability. Finally, one must consider space-time aliasing in the data, due to the finite time $(5.4 \mathrm{hrs})$ needed to make the azimuthal TL measurement.

\section{A. Circle distortion effects}

Let us first look at the simpler case of the upper OMAS1 track in Fig. 1(b), which shows both a distorted circle and a "center of the circle" (the sonobuoy) which drifted away from the true center. The simplest subset of this case to consider would be a true circle with the sonobuoys not at the center, but off center somewhere. In this case, the source to receiver distance would be azimuthally dependent and given, using simple trigonometry, by

$$
R^{2}=R_{c}^{2}+b^{2} \pm 2 R_{c} b \cos \varphi
$$

where $R$ is the source to receiver distance, $b$ is the displacement of the sonobuoy from the center position, $R_{c}$ is the radius of the circle, and $\varphi$ is the azimuthal angle. This azimuthal change in distance creates a change in TL in two ways. First, there is the overall spreading loss, which in the case of our data has been corrected approximately by applying a $15 \log R$ spreading law. As importantly, however, there is a change in the interference pattern with range, which occurs in shallow water over the scale of a half of the mode cycle distance, in our case $\sim 0.5 \mathrm{~km}$. By changing the source receiver range, one is effectively rocking the TL back and forth across the TL versus range plot, which can cause large apparent fluctuations, particularly in continuous wave (CW) signals. We have a broadband signal in SW06, which substantially lessens this effect. Moreover, this rocking back and forth occurs in a regular fashion for the simple case we described above, i.e. as a cosine dependence versus $\varphi$. Distortion of the circle will produce a similar effect, though not as easily describable in terms of a simple geometry.

Looking again at the actual source-to-receiver distances for the transmissions shown in Fig. 3, it is seen that the minimum distance is $7.1 \mathrm{~km}$, whereas the maximum distance is $8.6 \mathrm{~km}$, a $1.5 \mathrm{~km}$ distortion of the circle. If we now look at the TL versus range plots for an "average" transmission path (to try to approximate the system by a range independent one, so as to concentrate on experimental geometry effects), we obtain for $900 \mathrm{~Hz}$ the TL plots in Fig. 6 as calculated by the parabolic equation ( $\mathrm{PE}$ ) propagation model using representative sound speed profiles. This plot shows significant acoustic field variability over a few kilometers variation 
about the mean distance of $7.5 \mathrm{~km}$. If we plotted the CW TL versus the actual distance (which also corresponds to a given azimuth angle), we would obtain a nicely azimuthally variable result with structures on the order of $10^{\circ}$ width. This variability would be of order $15 \mathrm{~dB}$ peak-to-peak (as seen in Fig. 6), which is far larger than is seen, However, the actual measurement was broadband, and effectively averaged over frequency, reducing the size of the fluctuations. To account for this, the range averaging method proposed originally by Russian researchers (Chuprov, 1982), and expanded upon by Harrison and Harrison (1995), where one uses a range average of the TL to simulate a frequency average, is used. Specifically, we have that

$$
\frac{d \omega}{\omega}=\frac{d R}{R}
$$

so that we can simulate the $200 \mathrm{~Hz}$ bandwidth by an appropriate range average of the TL at each given R. Doing this, we obtain about $0.5 \mathrm{~dB}$ variability, which means that the geometric effect is only contributing a small amount of the variance seen in the broadband fluctuations (which are on the order of $2 \mathrm{~dB}$. See Table I).

The geometric variability effect we have discussed here is not at all unknown to ocean acousticians, but merely shows up in a different guise because we have now looked at the azimuthal dependence of TL with a fast moving vehicle, rather than examining the simple range dependence of TL.

There are other experimental cures for the $\mathrm{CW}$ fluctuations, in addition to broadband averaging. A moored vertical array can be used and have the vehicle circle around it. One integrates the energy in the vertical array coming through the water column (ignoring the bottom energy), and thus looks at the total energy arriving, which gets rid of interference pattern results at the receivers. Also, one can consider time integrated pulses, which also obviates array phase interference effects.

\section{B. Medium range dependence effects}

We next look at the case of a circular track in a range dependent environment. Given that we have excellent large scale environmental information about the ocean and seabed from SW06, it is worthwhile to do an $\mathrm{N} \times 2 \mathrm{D}$ PE model of the propagation with our best experimental input and see how this would produce azimuthal variability, both on fine and large angular scales. As discussed previously, the Scanfish towed vehicle provided us with the ocean variability on the larger scales (fronts, eddies, etc.). Objective maps of this larger scale variability were made each day, and a map of the soundspeed variability, with the OMAS tracks from September 8 superposed, is provided in Fig. 1(c), showing a top view of the variability.

The results from one slice of the $\mathrm{N} \times 2 \mathrm{D}$ PE model in one azimuth are shown in Fig. 7(a). Doing a dozen such slices over $360^{\circ}$ results in the TL plots shown in Figs. 7(b) and $7(\mathrm{c})$. Taking the set of modeled TL points at our intended circle diameter, $7.5 \mathrm{~km}$, we calculate a total variability of $0.8 \mathrm{~dB}$ standard deviation. Outside of the more volatile shelfbreak front bearings $\left(60^{\circ}\right.$ to $\left.180^{\circ}\right)$ the variability is reduced to only $0.3 \mathrm{~dB}$ standard deviation. This is significantly less than the $2 \mathrm{~dB}$ fluctuation we saw in the $5^{\circ}$ sector averaged TL data (see Table I), and we would thus conclude that meso-to-large scale variability in the coastal ocean may be one of the significant contributors, but is certainly not the only contributor to the fluctuations observed in the measured data.

Continuing our examination of possible contributors to azimuthal TL variability, it should be noted that there are also finer scale medium range dependence effects that can affect the azimuthal dependence of the TL curves. One particularly strong example is nonlinear internal waves, which are known to be very common at our experimental site. Satellite Synthetic Aperture Radar images [Fig. 8(a)] of the region show that this activity is spread over the entire region of our OMAS transmissions. The wavefronts are seen to be somewhat curved in this region, which destroys some of the alongshelf symmetry of the system, but the radius of curvature is of the order of $20 \mathrm{~km}$ or more, so that to first order we might approximate the waves as being linear and alongshelf in our area of interest. Thus, whatever the scattering by these waves, we can expect approximate alongshelf invariance.

The question of what the azimuthal dependence of the scattering of sound is by internal waves is also very interesting. Specifically, we would like to know if this scattering produces approximately $5^{\circ}-35^{\circ}$ wide beam pattern bumps in the TL, as seen in the data [Fig. 5(e)] and similar to what the larger scale oceanography produces. The theoretical answer to what caused this scattering pattern may be approached by using the "azimuthal sector diagram" proposed by Katznelson (Badiey et al., 2007), who showed that the azimuthal scattering by internal waves over a $90^{\circ}$ angular sector (which is repeated, by symmetry) has four major sectors. These are, where alongshelf and along the internal wave crests is zero degrees: the horizontal focusing regime (the $0^{\circ}$ to $5^{\circ}$ sector), the horizontal refraction regime (the $5^{\circ}$ to $10^{\circ}$ sector), the adiabatic regime $\left(10^{\circ}\right.$ to $\left.45^{\circ}\right)$ and the coupled mode regime $\left(45^{\circ}\right.$ to $\left.90^{\circ}\right)$.

The zero to five degree "ducted/focused" region is well known in the literature now, and can cause a peak of $\sim+/-5^{\circ}$ width in that angular sector. However, due to the fact that the internal wave directional spectrum is not purely onshore, but has an angular spread of $\sim 30^{\circ}$ [Fig. 8(b)], we expect $+/-15^{\circ}$ of the theoretical $90^{\circ}$ angular sector of TL to be susceptible to these "focusing peaks" which are of order $5^{\circ}$ width. Past the focusing sector is the "horizontally refracted" sector, in which energy refracts outside the IW horizontal duct, but still propagates at low angles. In addition to this, one can look at the reflection of sound from straight or curved internal waves at low angles-it is the same angular regime. An example of what happens to this low angle sound in the horizontal direction is shown in Fig. 8(c). In this figure we see that the horizontally reflected and refracted sound forms beams at up to $10^{\circ}$, and with widths of $\sim 1^{\circ}$ to $5^{\circ}$. Again, the angular spectrum of the internal waves allows this effect to be seen up to about $+/-25^{\circ}$ relative to alongshelf. The next regions one should consider in the azimuthal direction are the adiabatic and coupled mode regimes. 


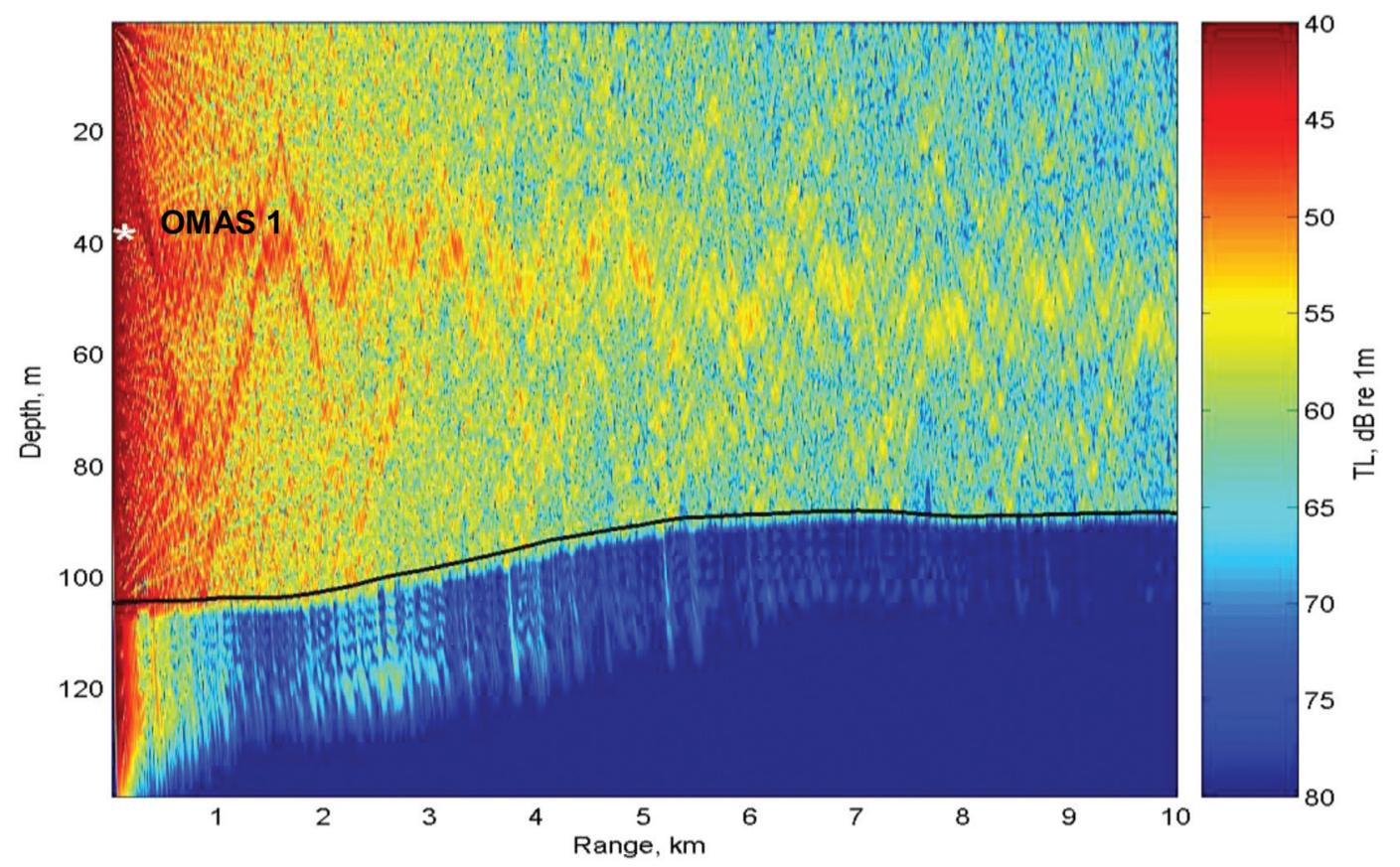

(a)

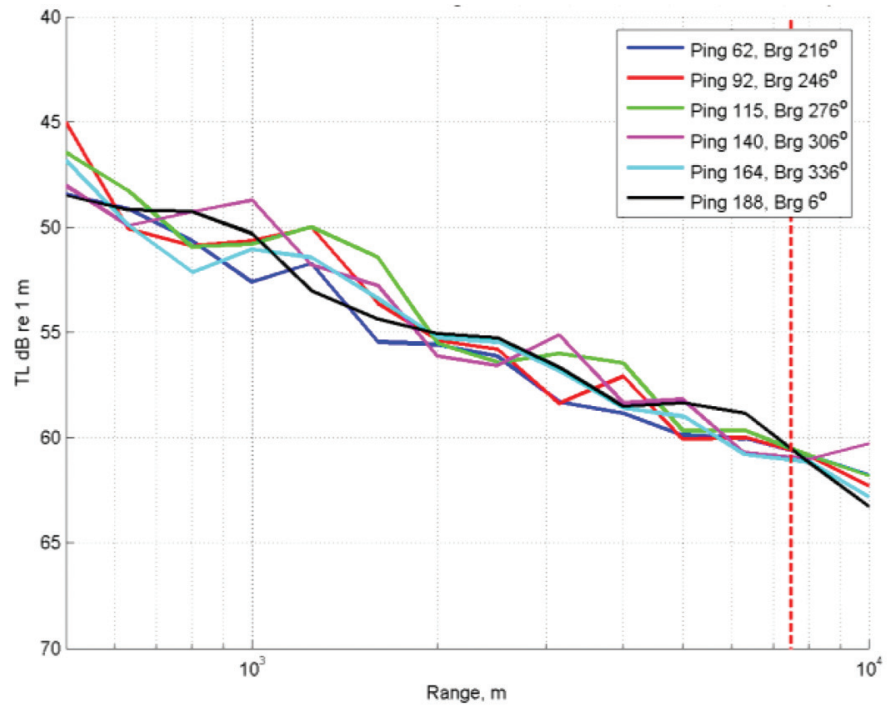

(b)

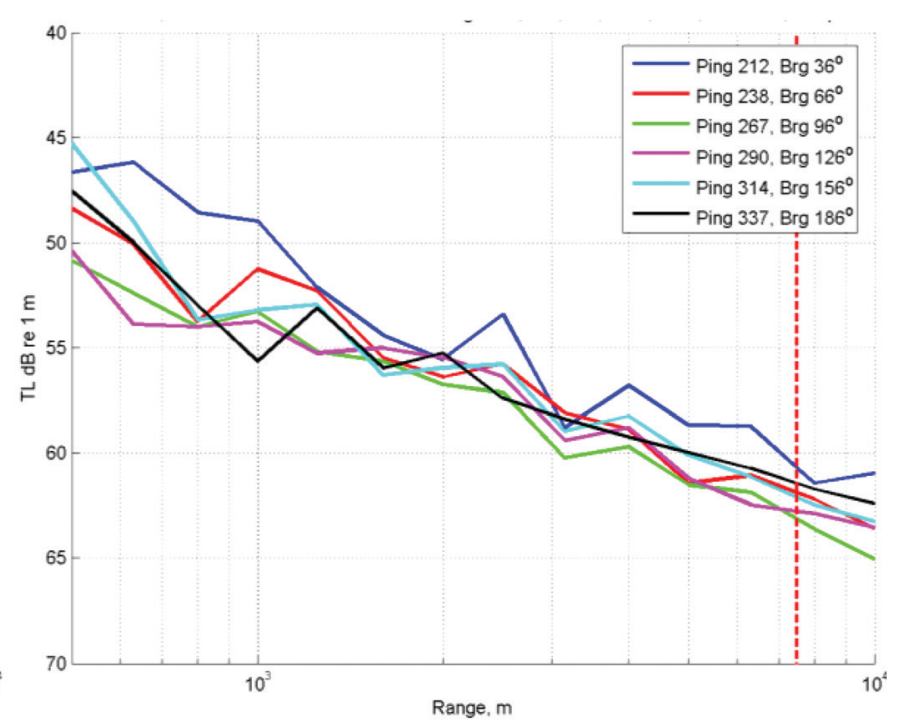

(c)

FIG. 7. (a) Full-field OMAS1 to OMNI $1900 \mathrm{~Hz}$ TL model output for one of twelve modeled azimuthal source/receiver positions over the $360^{\circ}$ of the circle. (b) and (c) OMAS1 to OMNI1 $900 \mathrm{~Hz}$ TL model results. Third-octave range averaged TL vs. range for twelve source/receiver positions are shown. Note the dashed red line denoting the intended source to receiver range of $7.5 \mathrm{~km}$. Source and receiver were at depths of $40 \mathrm{~m}$ and $61 \mathrm{~m}$, respectively.

Mechanisms for beaming in these regimes are also quite feasible, but since the derivations and details are lengthier, we leave them for Appendices A and B. Rather, we will just briefly discuss the results here.

For the adiabatic regime, by considering a path which goes through a nonlinear internal wave compared with an equal length path that does not, one can see what azimuthal angle difference the two paths have to be for a given mode cycle distance to move out of phase $180^{\circ}$, or equivalently to go from a peak to a null in the TL curve. These calculations give us a peak width of about three degrees for $600 \mathrm{~Hz}$ and $900 \mathrm{~Hz}$, in approximate agreement with the type of peak width we see in the data. Finally, looking at the coupled regime, we use the resonant mode coupling condition (Zhou et al., 1991), along with a criterion for the width of a coupling resonance, to approximate the peak width would be in this regime. We find that the width is about $10^{\circ}$ to $45^{\circ}$ at a $45^{\circ}$ angle to the wave, and less than that as one approaches $90^{\circ}$ incidence.

All these results are consistent with small, sharp peaks in the TL versus angle plot, with some broader peaks due to coupling. Thus, it is plausible that transmission through internal waves can also produce the types of effects we see in our data. 

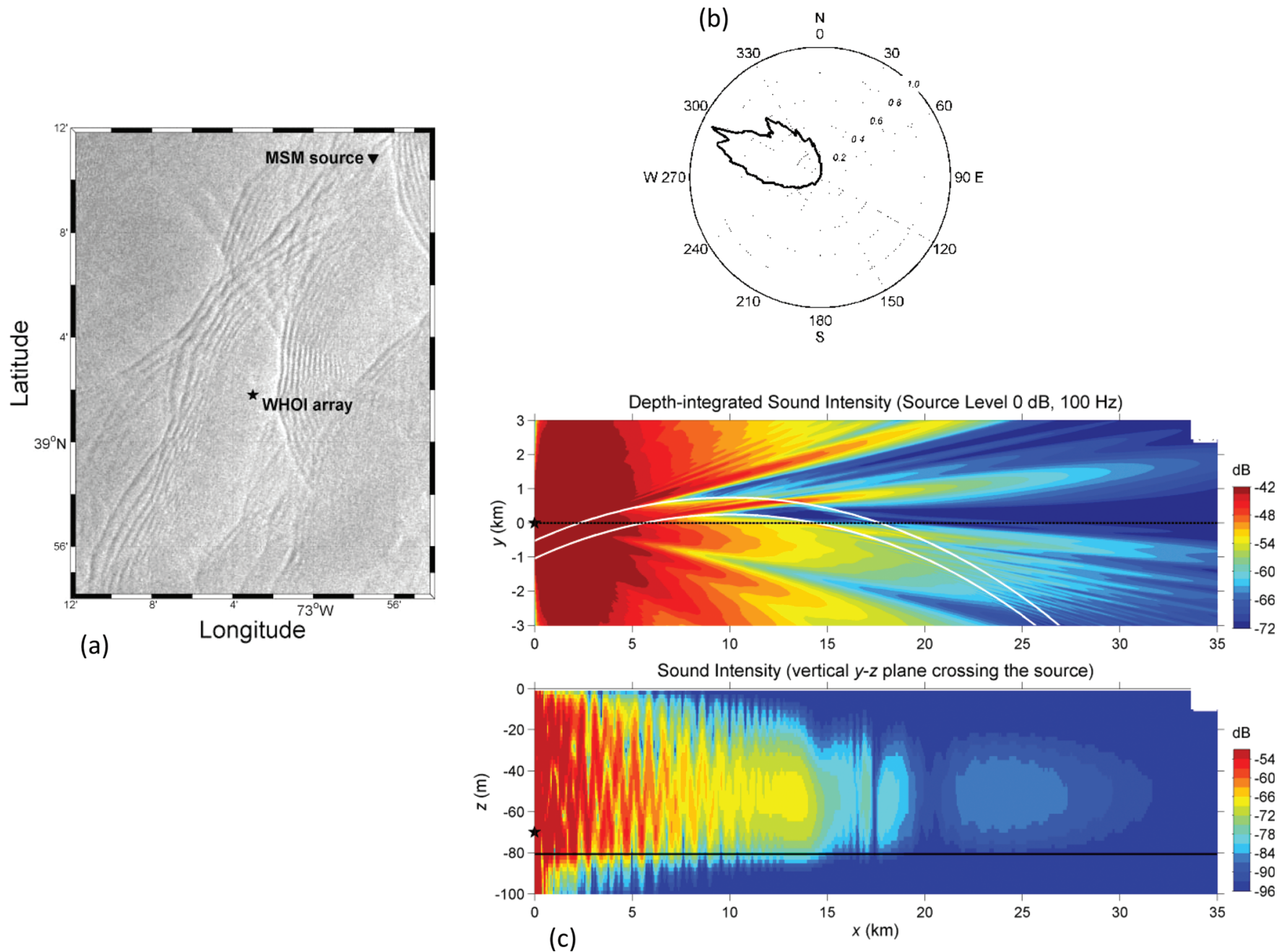

FIG. 8. (a) Satellite synthetic aperture radar (SAR) image on July 23, 2006 which shows internal wave activity in the region of the OMAS acoustic transmissions. (b) Angular spectrum of nonlinear internal wave directions during the SW06 experiment. (c) Horizontal acoustic beams in the refracted/reflected region, resulting from a 3D sound propagation model.

\section{Three less usual suspects: finescale bathymetry, fish, and 3D slopes and canyons}

In looking at azimuthal symmetry and horizontal invariance in TL, three effects are commonly ignored: (1) finescale bathymetry, which is often smoothed over for convenience, or included as stochastic roughness, (2) fish schools and shoals, which can have significant attenuation and scattering effects from (roughly) $700 \mathrm{~Hz}$ to many kilohertz frequencies, and (3) fully 3D (including the acoustics) continental slope and canyon effects.

\section{Finescale bathymetry effects}

Finescale bathymetry (order $10 \mathrm{~m}$ to $100 \mathrm{~m}$ resolution), which is often either unavailable or is lowpass filtered out for computational convenience, can introduce significant (several dB) fluctuations into transmission loss, both narrowband and broadband. There are some dominant mechanisms that do this, which we will briefly discuss here. They are: (1) mode coupling (when the acoustic track crosscuts the bathymetry at a significant angle, such that one sees large local slopes), and (2) fully 3D acoustic ducting, refraction, lateral reflection and shadowing from bumps and from ripples aligned along (or nearly along) the acoustic track.

Mode coupling due to bottom roughness is a well known and much studied effect. Bottom roughness spectra are usually treated as azimuthally isotropic and translationally invariant, which has led to azimuthal variability in TL due to bottom roughness mode coupling being largely ignored. This is justifiable if one looks at an average over many realizations of the bottom, but is not for a single bottom roughness realization, even with isotropic statistics. In the SW06 region we are studying, the bottom roughness, from high resolution bathymetry charts, is in fact not azimuthally isotropic, but rather has some along-shelf structure. We thus will deal with the explicit bathymetry as follows. We do not present mode coupling calculations with this roughness included (though this can easily be done using the parabolic equation model), as we feel this is old ground. We do, however, look at some of the along-shelf 3D acoustics effects going along shelf, as is discussed next.

The second set of effects mentioned, fully 3D ducting, refraction, lateral reflection, and shadowing, are potentially capable of introducing large azimuthal TL variations, as we 
3D Adiabatic Modal TL (Mode 2, $100 \mathrm{~Hz}$ ) over Rough Seafloor

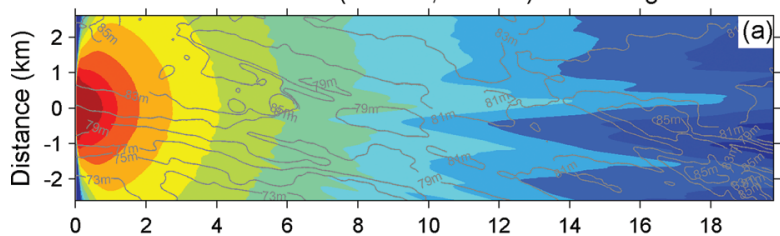

Nx2D Adiabatic Modal TL (Mode 2, $100 \mathrm{~Hz}$ ) over Rough Seaflool

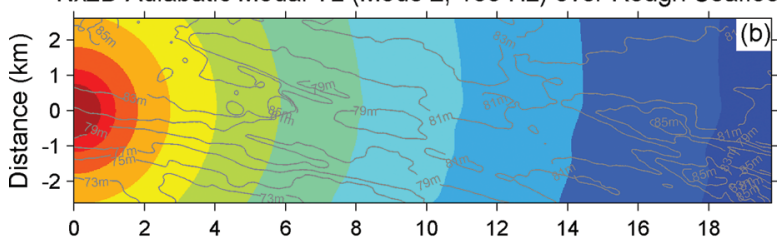

3D Adiabatic Modal TL (Mode 2, $100 \mathrm{~Hz}$ ) over Smooth Seafloor

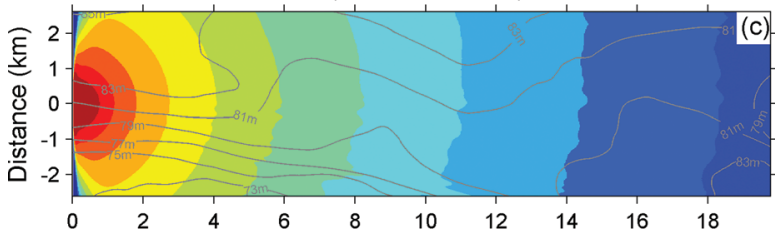

3D Adiabatic Modal TL (Mode 12,600 Hz) over Rough Seafloor

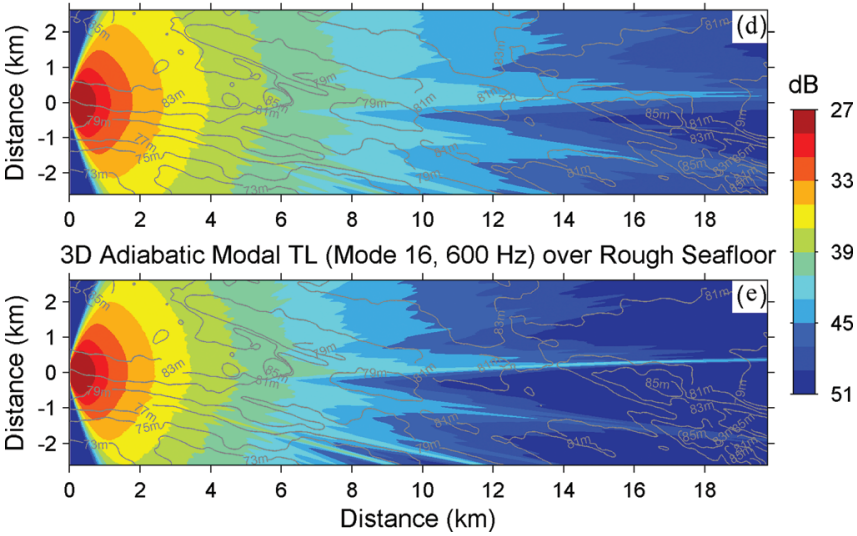

FIG. 9. (a) Fully 3D adiabatic propagation over real finescale bathymetry, showing beaming of energy in horizontal. (b) $\mathrm{N} \times 2 \mathrm{D}$ calculation with same bathymetry as panel "a", but not showing beaming, thus indicating effect is fully 3D. (c) Smoothed bathymetry with full 3D calculation, showing that lowpass filtering of bathymetry can eradicate this finescale horizontal beaming effect. (d) and (e) Fully 3D calculations of horizontal beaming at $600 \mathrm{~Hz}$ due to bathymetry, showing that this effect increases with increasing mode number.

will show using vertical-mode and horizontal parabolic equation (PE) modeling along with the high resolution bathymetry of the SW06 region. Our vertical-mode and horizontal PE model is a full 3D sound propagation model without mode coupling effects, and we will note that the 3D sound propagation effects of finescale bathymetry are mainly seen when the angles between the acoustic track and the alignment of the bathymetric features are small.

In Fig. 9, we show two panels of fully 3D and one panel of $\mathrm{N} \times 2 \mathrm{D}$ PE TL calculations at $100 \mathrm{~Hz}$ (a simpler frequency to compute), geographically below where our OMAS data is in latitude, but illustrative of the effects we wish to observe, and also (as will be seen) consistent with $600 \mathrm{~Hz}$ calculations, showing the rather broadband nature of the effects. In the upper panels, Figs. 9(a) and 9(b), we display the TL for mode two at $100 \mathrm{~Hz}$, with panel 9(a) showing a full 3D result, and panel 9 (b) showing an $\mathrm{N} \times 2 \mathrm{D}$ result. In panel 9(a), horizontal reflection of sound by a bathymetry feature near the source creates a mode two shadow zone and two caustics surrounding it, a fully 3D acoustics effect, which is evident since this effect is not seen in the $\mathrm{N} \times 2 \mathrm{D}$ calculation in panel 9(b). Moreover, we would note that the angular width of the shadow zone we see is $\sim(1 / 10) * 57^{\circ}$, or $5.7^{\circ}$, right in the domain we saw the fluctuations in our data. We will see that this angular sector is, to a first approximation, frequency independent.

In Fig. 9(c), we show the same calculations for $100 \mathrm{~Hz}$, but now with a smoothed bathymetry. Unsurprisingly, these effects totally disappear. The contrast between the high resolution bathymetry 3D TL result and the smoothed bathymetry result is a large one. In the former, we see a $10 \mathrm{~dB}$ (peak to null) azimuthal variation between the shadow zone and the caustics, whereas in the latter, we see no significant azimuthal variation at all.

In Figs. 9(d) and 9(e), we show two fully 3D, high resolution bathymetry TL calculations, but now for $600 \mathrm{~Hz}$, and for modes 12 and 16, respectively. It is seen from the contrast between the different panels in this figure that the angular regime which sees the shadow zone and caustics is nearly identical for the two frequencies, which comes from the fact that the "horizontal modal rays" one gets from the Weinberg-Burridge picture of this propagation (Weinberg and Burridge, 1974) go through very similar horizontal index of refraction fields. One also sees that the effect is stronger as one goes to higher modes, which again makes sense, as the higher modes interact with the bottom at higher angles, and are thus more significantly impacted.

\section{Fish school and shoal effects}

One large unknown as far as understanding propagation fluctuations on the continental slope and shelf is fish schools and shoals, which can produce large attenuation of transmissions, as well as scattering of energy (reverberation). As we generally do not know the location, size, or compositions of the fish schools, they add a completely unknown error term to experiments such as the ones we have described. As mentioned, the size of the attenuation due to fish can be considerable; Diachok saw $5-8 \mathrm{~dB} / \mathrm{km}$ attenuation at $800-1500 \mathrm{~Hz}$ due to sardines in an experiment in the Gulf of Lion (Diachok, 2005), and this is not atypical of what one might see from other species in other places. Fishing activity was noted in SW06, particularly near the shelfbreak, and on the slope and in canyons. Thus, we must admit to an uncertainty from this effect. In that the majority of our acoustic track was further onshelf, this effect may be somewhat reduced, however.

\section{Slopes and canyons}

Perhaps the most complicated areas of the ocean to describe, from almost any viewpoint, be it acoustics, physical oceanography, geology, or biology, are the continental slopes and the marine canyons the often cross cut them. Our SW06 data does have segments going across the continental slope, but we purposely distanced ourselves from the marine canyons in the preliminary experimental design. The TL for 
the segments going across the slope will have considerable uncertainty, due to the fact that the oceanography, subbottom geology, and biology (fish) are highly variable, and are not well measured compared to other portions of our experimental site. However, as shown in Sec. V B, the TL computed with simple range dependent $2 \mathrm{D}$ propagation tracks, the measured oceanography, and the bottom geoacoustic model for the central site is within a few $\mathrm{dB}$ of the measured values, giving us some confidence that we have at least a first order working model of the slope.

\section{Spacetime aliasing of the azimuthal measurements}

The previous section dealt with the physical causes of the azimuthal variability observed. In this section, we will look, as in Sec. V A, as to what measurement error does to the observed azimuthal variability. In particular, we will look at space-time aliasing due to the finite speed of the vehicle, which distorts the angular variability pattern that is observed. Specifically, if a vehicle is moving very fast compared to the speed of an ocean feature, then the ocean is effectively "frozen" during the interval of the measurement, and thus the angular variability is measured correctly. However, if the vehicle speed is similar to or slower than the ocean feature speed, then the angular width of the peak will be broadened compared to an "instantaneous snapshot measurement."

Regarding our SW06 data, the OMAS vehicles move at $\sim 2.5 \mathrm{~m} / \mathrm{s}$ (5 knots), circling the $7.0 \mathrm{~km}$ radius track (circumference about $43 \mathrm{~km}$ ) in about five hours. By comparison, mesoscale features (of scale $5-7 \mathrm{~km}$ in this region) take about one day to transit past the observation circle, and so are "reasonably sampled" in angle. The $12.4 \mathrm{hr}$ M2 tidally locked phenomena such as internal tides are less well sampled, however, and the nonlinear internal waves, which move at the same speed as the internal tides (actually, a little faster) also are not sampled well.

To attempt to quantify the angular smearing due to space-time aliasing, let us look at the case of a nonlinear internal wave transiting across the circular track made by an OMAS vehicle in our experiment. Specifically, by looking at how long it takes an OMAS to transit the scale length of a feature in its direction of propagation (using the relative velocities of the vehicle and wave), one can estimate what angular sector is covered during the measurement interval versus the angular sector that the feature itself subtends. For a straight line internal wave of scale $\boldsymbol{l}_{\boldsymbol{I} W}$, the relative velocity of the wave and the vehicle is:

$$
\vec{v}_{r e l}=\vec{v}_{I W}-\vec{v}_{O M A S}
$$

which for a wave travelling across shelf (shoreward) can be conveniently looked at through the $y$-component equation:

$$
v_{r e l}=v_{I W}-v_{O M A S} \cos \left(\omega t+\theta_{0}\right)
$$

Here, $\omega$ is the angular speed of the OMAS and $\theta_{0}$ the angular initial condition (where the vehicle is initially on the circle). To see how long it takes the OMAS to transit a feature scale length, we just integrate the above equation over time, giving

$$
v_{I W} T-\frac{v_{\text {OMAS }}}{\omega} \sin \left(\omega T+\theta_{0}\right)=l_{\text {scale }}
$$

Solving the above for $T$, we get the additional time the oceanographic feature takes to transit relative to the OMAS, which determines in turn how much more angular space the feature seems to subtend when measured by a moving vehicle.

Consider an internal soliton of typical width $100 \mathrm{~m}$ propagating across the circular OMAS track(s) we showed in Fig. 1(b). Such a soliton at the top of the circular track subtends an angle of $9.68^{\circ}$. At the top of the circle, the OMAS velocity is purely along the wave, and not across it, so that the transit time of the OMAS across the wave is, to a good approximation, determined by the across shelf speed of the wave. Converting this into an angular spread gives $\sim 2.5^{\circ}$, or an approximately $25 \%$ increase. For the wave crossing the center of the OMAS circle, the angular dimension of the wave is smaller, about $0.8^{\circ}$. In this scenario, there are two cases: the OMAS going with the wave and against the wave, which give slightly different results. The spreads are $1.0^{\circ}$ with the wave and $0.6^{\circ}$ against the wave, which are of the same order as the angular extent of the wave on the circle. Thus, we see that space-time aliasing of the measurement needs to be taken into account for angular spectra.

\section{E. Synopsis of the error budget}

It might be useful at this point to present a brief synopsis of an error budget in TL and angle, so as to convince the reader that the error is smaller than the observed TL versus angle variability signal.

Beginning with TL error, there is a small $0.25 \mathrm{~dB}$ source calibration error, which is probably best relegated to the mean signal observed versus azimuth. There is also a potential $0.5 \mathrm{~dB}$ source level variability during the course of the experiment, which is not a bias. Corrections for the noncircular track are comprised of a mean (cylindrical spreading) term and an interference pattern term. The cylindrical spreading correction has only a very slight error in it, due to the $\sim 50 \mathrm{~m}$ error in source range estimation one encounters from the triangulation (over a $7 \mathrm{~km}$ path), and can be neglected. The error in the interference term, after reduction by broadband averaging, is of order $0.25 \mathrm{~dB}$. If we simply add the variances of the source level and interference errors and take the square root, we would see an error of roughly $0.5 \mathrm{~dB}$, which is much smaller that the variability in the signals observed in the data.

The errors in the angle measured come from two sources: (1) the source $x$ - $y$ position error and (2) the finite speed of the vehicle. A horizontal deviation of $\sim 50 \mathrm{~m}$ over $7000 \mathrm{~m}$ gives about a 0.4 degree error in angle, which is the maximum we would expect from this source. An average number may be about half this. Our finite vehicle speed errors, as discussed in the last section, were on the order of 0.6 to 1.0 degrees, depending upon the position along the circular track. Again, simply adding the square of the errors and 
taking the square root gives $\sim 1.1$ degrees maximum error, rounding to the nearest tenth of a degree. This is a small angular error, and certainly smaller than the peak widths observed in the data. We also note that our sampling time was consistent with a 1.0 degree resolution in angle at the $7.1 \mathrm{~km}$ average distance.

\section{THE ROLE OF INTRUSIONS IN DEVELOPING ALONGSHELF ASYMMETRIES IN TRANSMISSION LOSS}

Let us now return to the issue of large scale horizontal/ translational invariance. While the circular patterns of the mobile acoustic sources on September 8 suggest that there are not significant differences in transmission loss over alongshelf scales of $15 \mathrm{~km}$ shoreward of the shelfbreak front, conditions earlier in the experiment offer a clear example of when this is not the case. As discussed, the cold shelf water (comprising what we have termed the Cold Pool Duct) was located substantially further shoreward before Tropical Storm Ernesto, during August 25-31. During this time period, a warm core ring directly abutted the shelfbreak front and drove thermohaline intrusions onshore across the $80 \mathrm{~m}$ isobath. These intrusions were associated with warm anomalies (slope and warm core ring water masses) leading to substantial alongshelf variability in the temperature field (and thus soundspeed) along the $80 \mathrm{~m}$ isobath.

A good example of the alongshelf temperature variability is the alongshelf section at the $80 \mathrm{~m}$ isobath from August 28 [Fig. 10(a)]. Within this section, there is a $15 \mathrm{~km} \mathrm{seg-}$ ment associated with a sub-pycnocline saline intrusion in which the thermocline is substantially weakened relative to the shelf water on either side of the intrusion. Within the intrusion, the temperature minimum shifts from between $30-40 \mathrm{~m}$ depths in the shelf water on either side of the intrusion to a depth of $62 \mathrm{~m}$ at $x=12 \mathrm{~km}$ within the intrusion. Similarly, the minimum temperature goes from $1484 \mathrm{~m} / \mathrm{s}$ to $1495 \mathrm{~m} / \mathrm{s}$ within the intrusion. Note the track of the August 28 OMAS in red and the drifting sonobuoy receiver in green, overlaid on the temperature data in Fig. 10(a). The OMAS tracks consist of repeated reciprocal legs of $10 \mathrm{~km}$ on generally northeasterly/southwesterly headings, originating near the receiver. Overlaid on the temperature plot, one can see that the intrusion introduces significant range-dependence to the sound speed field through which the OMAS traveled.

The impact of the intrusion on the straight line track transmission loss can be seen in Fig. 10(b). The figure shows that the transmission loss increased by roughly $10 \mathrm{~dB}$ between ranges of 3 to $7 \mathrm{~km}$. While further detailed analysis is beyond the scope of this paper and will be pursued in future studies, we note that this rapid increase in transmission loss occurred as the mobile source crossed the region of the intrusion. Thus, we stress that the azimuthal homogeneity shoreward of the shelfbreak front is limited to conditions in which there is an absence of intrusions and other features such as frontal meanders that would induce significant alongshelf variability in the temperature and soundspeed fields over the shelf.

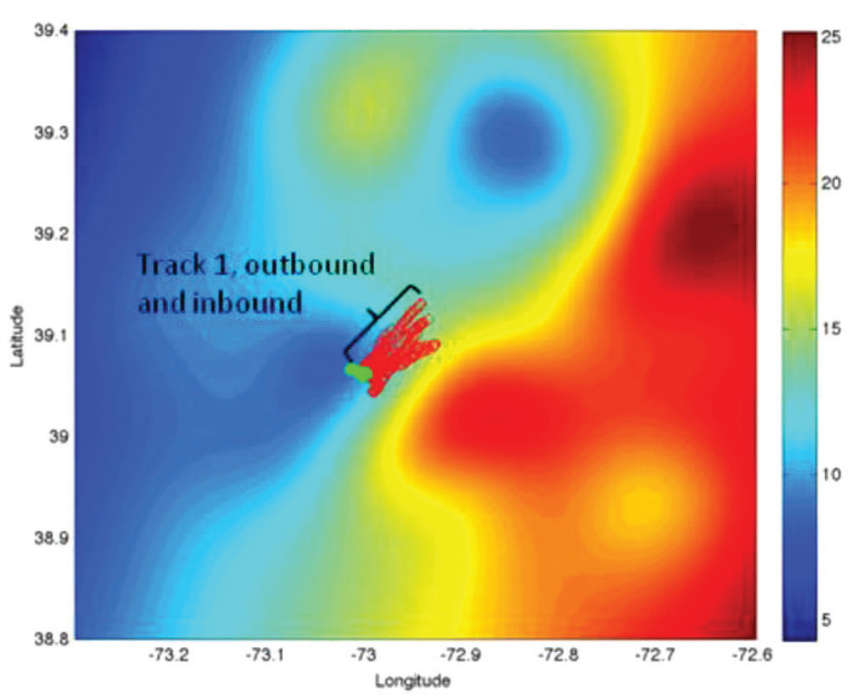

(a)

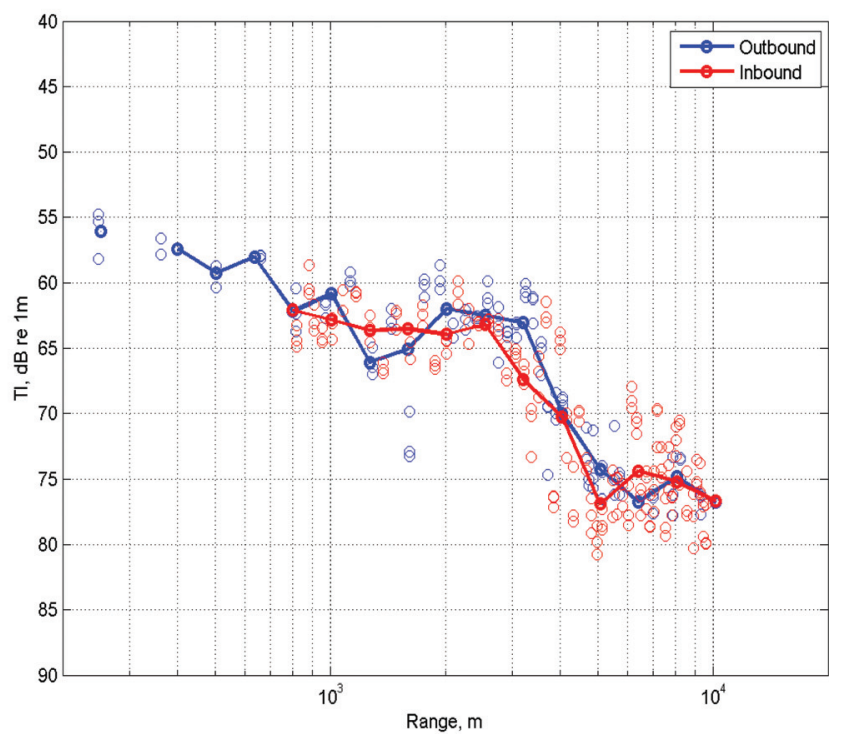

(b)

FIG. 10. (a) Tracks of alongshelf August 28, 2006 OMAS transmissions across an intrusion. OMAS tracks are shown in red, with the receiver shown in green. Both are overlaid on a color plot of water temperature at $30 \mathrm{~m}$ depth. (b) Transmission loss curves for the OMAS transmissions across an intrusion, showing a sharp drop off at the range of the intrusion.

\section{DISCUSSION AND CONCLUSIONS}

What we have presented in this paper is in many ways a first look at the data, theory, and modeling needed to understand the azimuthal variability and translational invariance issues for low to medium frequency shallow water propagation, ranging from $500 \mathrm{~Hz}$ to $1000 \mathrm{~Hz}$. We firmly believe that this problem justifies more work in the future, and so in this section we will discuss both where we are presently and where we think we should go.

\section{A. Experimental details}

The circular track data that was presented in this paper, which resolves azimuthal variability to approximately a degree, is of a type not commonly seen or reported in the 
ocean acoustics literature. The use of relatively fast autonomous underwater vehicles (AUV's) with onboard sources transmitting to fixed, moored or slowly moving sonobuoy receivers now makes this measurement possible

In terms of the environmental support for such measurements, the SW06 experiment had excellent resources for measuring the large and mesoscale oceanography, the finer scale internal wave field, and even the bottom properties (though the bottom measurements over the slope were lacking compared to the very careful on-shelf measurements.) However, the effects of the biological field (fish schools and shoals) were not measured, so that there is some remaining ambiguity due to that unknown.

Concerning the acoustic variables measured, we only looked at two acoustic frequencies at fixed radius $(\sim 7.5 \mathrm{~km})$ circular tracks, and two frequencies over a straight track at a fixed distance from the shelfbreak for the along-shelf work. The high-resolution azimuthal variability dependence is assuredly range/radius and frequency dependent (due to the attenuation, dispersion, and scattering mechanisms that cause such variability), and so we certainly could and should do more sampling of these two important parameter spaces. For the along-shelf variability, one needs to look at tracks as a function of distance from the shelfbreak, as the ocean and seabed will vary with distance from the shelfbreak. This is not to minimize the value of the initial data that we have taken, but just to point out that there is a fuller problem to be addressed.

Also, as regards the acoustics, we would note that we looked at broadband processing using the peak of the matched field output in this paper. This is a choice one can make in looking at fluctuations, but it is certainly not the only choice. Looking at broadband data gives us some useful averaging of the fluctuations, which can reduce the "variable radius" errors, as discussed in the text. However, it reduces the size of the overall fluctuations (the signal size), so this is somewhat of a tradeoff. Using the peak of the matched filter output gives us the largest signal level to look at, and is relevant to the peak detection problem. Alternatively, one can look at the total integrated energy over the whole pulse arrival sequence, which is more relevant to the properties of energy detectors. This was not done here, as the energy detector study needs a high SNR across the whole pulse, which was not available in our SW06 data.

There is also the experimental problem of the spacetime aliasing of the acoustic data, especially when due to the faster ocean processes like internal waves. This is a hard problem, particularly if one wants to sample the azimuthal pattern at a high angular resolution. At present, our best tactic is to estimate the "broadening" effects of such aliasing.

\section{B. Implications of our measurements}

In Sec. IV above, we asserted that ping-to-ping TL variability makes some degree of averaging over azimuth necessary. We examined two different sector widths, $15^{\circ}$ and $5^{\circ}$. The wider binning had the effect of averaging out fine-scale fluctuations and showed that the mean TL was both isotropic and translationally invariant over a $12.5 \mathrm{~km}$ along-shelf separation outside of the oceanographically more complex shelfbreak front region. This effect of the front on TL isotropy and invariance is not an unexpected result. (Again, this is primarily due to upslope propagation, a well known propagation condition.) On the flatter part of the shelf, away from the front, eddies, and slope, one would expect azimuthal symmetry to hold better.

The finer $\left(5^{\circ}\right)$ binning showed that fine-scale mean TL is neither isotropic nor translationally invariant, and is generally unpredictable (random) in nature. Even in our broadband data, azimuthal fluctuations of a few $\mathrm{dB}$ are seen when looking at the smaller angular bins. Fluctuations of this magnitude seem to be most consistent with internal wave scattering and bathymetry irregularities, as suggested by our modeling and theory. An interesting note should be made about this hypothesis that internal waves are a strong, and perhaps dominant, effect on the finescale azimuthal variations. Specifically, in similar OMAS measurements in the deep $(1350 \mathrm{~m})$ waters near the Bahamas, on a day where there was little to no internal wave activity (and little to no bottom interaction), there was virtually no azimuthal variability seen in the TL data $\left(\sigma=0.5 \mathrm{~dB}\right.$ for $5^{\circ}$ sector averaged data. See Appendix C). However, in (again similar) OMAS TL data from the East China Sea where there was significant nonlinear internal wave activity, large TL fluctuations were observed. That data is in the process of being reported. [C. Emerson, private communication] Thus, we are at the stage of having a working hypothesis for the major causes of the azimuthal variability, and have some initial data that seems consistent with these conjectures.

We should also note that our hypothesis that the finer scale azimuthal peaks are due to ducting, refraction, and adiabatic effects, whereas the broader peaks are due to coupling effects, is one that is currently hard to prove with the present experimental data due to the irregularity of the internal wave field "smearing" these effects. However, this hypothesis might be provable in two other ways, which we discuss next.

The first way this hypothesis might be proved is to look at time integrated TL data, which is not available from our SW06 data (due to SNR issues), but which is available from recent experimental work we have done in the East China Sea (ECS). For an integrated TL measurement, one does not see the phase interference effects that characterize the refracted and adiabatic regimes, which in turn produce most of the narrow peaks for the peak TL measurement. Rather, one sees only the two effects of focusing (which moves energy in and out of the source/receiver plane) and mode coupling (which can increase or decrease the total energy received by changing the modal amplitude distribution and thus the overall attenuation). For an integrated TL measurement, one then expects to see mostly very broad peaks (coupling) with a few narrow peaks (focusing) interspersed. This is what our preliminary looks at the ECS integrated TL data seem to indicate, though more work needs to be done, and we cannot yet say this is a solid result.

Second, one can consider 3D sound propagation modeling for a simulated ocean with mesoscale and "simple, plane wave" internal wave fields in order to understand the 
azimuthal effects of these fields, and indeed this was done by Oba and Finette (2002) to predict the "ducted focusing" effect and acoustic horizontal array coherence lengths. One could extend this work to decomposing the acoustic field generated by PE into modes (e.g., via a computational vertical array mode filter), and then see if the modal mechanisms we suggested are correct.

One shortcoming of the computer approach at present is that we do not have a realistic, 4D internal wave field, due to the current state of ocean internal wave models. Regional coastal oceanography models work well down to mesoscale and even internal tide scales, but cannot incorporate all the oceanography down to the second and meter scales required for including nonlinear internal waves. Research is currently under way to develop just such models (Duda, private communication), but at present, simplified models have to be used.

\section{Future experiments}

As mentioned, the experimental configuration for the study of both azimuthal and translational invariance effects is rather simple, consisting of a fast, source bearing UUV and a fixed, moored receiver. A source bearing a wider range of frequencies would be desirable, as would a vertical array receiver. Exploration of the circle radius space (for azimuth) and the range from the shelfbreak space (for translational invariance) would also be desirable. The environmental support of a Scanfish survey for mesoscale effects and a few thermistor moorings for internal wave field estimation should be sufficient for the physical oceanography. Estimation of the bottom properties by inverting the acoustic TL curves should be adequate to address that part of the problem. Finally, we would suggest that an UUV vehicle equipped with a sidescan sonar and camera to estimate fish populations also be employed at the experimental site, thus closing out the last (we think) major source of environmental uncertainty.

\section{Concluding remarks}

To conclude, we should provide a concise answer to the question posed by the paper's title: are azimuthal isotropy and horizontal invariance seen in the SW06 circular and linear track TL data we discussed in the paper? Let us first look at azimuthal isotropy. Based on the preceding discussions, the simple answer(s) are: (1) yes, if one looks at a region containing no large scale horizontal soundspeed gradients, and if one averages over angular sectors of $\sim 10$ degrees or more, but (2) no, if one looks at finer angular resolution bins, where fine scale oceanography and bathymetry can readily create peaks of 1-10 degrees width. Regarding alongshelf translational invariance, the conclusions are similar. In the absence of large scale alongshelf soundspeed gradients, the azimuthal variability is translationally invariant when averaged over larger angular bins, but not when looked with finer angular resolution. An interesting note is that the statistics of the finescale angular fluctuations may be stationary alongshelf if the fine scale oceanography/bathymetry processes that drive the fluctuations are. Finally, in looking at both the circular and linear tracks, one sees that the largescale features such as the shelfbreak front and warm water intrusions can easily disrupt both the azimuthal isotropy and alongshelf translational invariance of TL.

\section{ACKNOWLEDGMENTS}

The authors would like to thank Dr. Terri Paluszkiewicz, Dr. Ellen Livingston and the Office of Naval Research Code 32 for their continued support of this work, and the Captain and crew of the R/V Endeavor for their hospitality and able assistance. Thanks also go to Dr. Ira Dyer for his insights on TL isotropy and translational invariance, to Andrey Shcherbina for providing the graphics for Fig. 2, and Hans Graber for providing satellite SAR imagery of the internal wave field.

\section{APPENDIX A: ADIABATIC REGIME OF INTERNAL WAVE EFFECTS}

Consider Fig. 11(a). In this figure, we wish to examine the change in modal phase difference between two modes (i.e., their cycle distance) along two paths, OA and OB. Path OA does not go through an internal wave soliton, whereas path $\mathrm{OB}$ does. If we get that the phase difference between these two cycle distances changes by $180^{\circ}$, then the

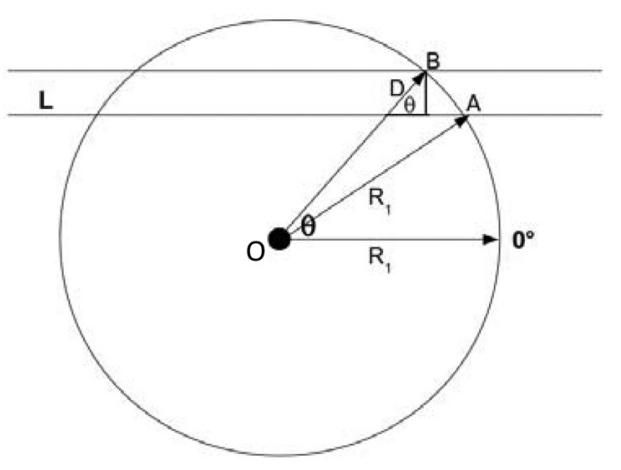

(a)

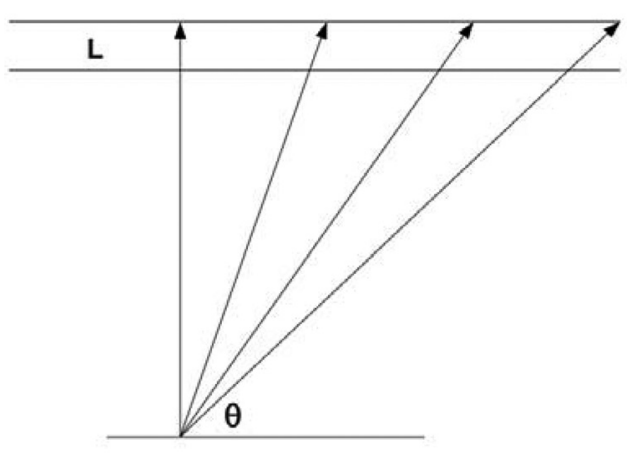

(b)

FIG. 11. (a) Equidistant paths, one crossing and the other not crossing an internal wave soliton. (b) Various paths crossing an internal wave soliton. 
azimuthal transmission loss (TL) pattern should go between a peak and a null, i.e., this is a measure of the azimuthal beamwidth for a major fluctuation in TL.

We write this mathematically as:

$$
\begin{aligned}
\Delta k_{n, m}^{\text {new }} & =\left(k_{n}+\Delta k_{n}\right)-\left(k_{m}+\Delta k_{m}\right) \\
& =\Delta k_{n, m}^{\text {old }}+\left(\Delta k_{n}-\Delta k_{m}\right) .
\end{aligned}
$$

The criterion for $180^{\circ}$ out of phase is

$$
\left(\Delta k_{n}-\Delta k_{m}\right) \frac{L}{\sin \theta}=\pi .
$$

If we use a perturbation theory expression for a rigid bottom waveguide and a simple "square wave" perturbation due to the internal waves, we get

$$
\Delta k_{n}=\frac{-1}{k_{n}} \frac{\omega^{2}}{c_{0}^{2}} \frac{\Delta c}{c_{0}} \frac{H_{I W}}{H} .
$$

Combining Eqs. (A2) and (A3) gives

$$
\frac{\omega^{2}}{c_{0}^{2}} \frac{\Delta c}{c_{0}} \frac{H_{I W}}{H}\left[\frac{k_{n}-k_{m}}{k_{n} k_{m}}\right] \frac{L}{\sin \theta}=\pi .
$$

If we now put in an approximation for the bracketed term in Eq. (A4),

$$
\left[\frac{k_{n}-k_{m}}{k_{n} k_{m}}\right] \sim \frac{1}{k} .
$$

We obtain an approximate form:

$$
\frac{\Delta c}{c_{0}} \frac{H_{I W}}{H} \frac{k L}{\sin \theta}=\pi
$$

If we are in the adiabatic regime, solving for $\theta$ should give angles in the $20^{\circ}-45^{\circ}$ sector. Putting in typical numbers: $\Delta c=40 \mathrm{~m} / \mathrm{s}, \quad c_{0}=1500 \mathrm{~m} / \mathrm{s}, \quad H_{I W}=10 \mathrm{~m}, \quad H_{I W}=100 \mathrm{~m}$, $k=(2.51$ and 3.76$)$ for $600 \mathrm{~Hz}$ and $900 \mathrm{~Hz}$, respectively, and $L=200 \mathrm{~m}$ (a typical width of an ocean soliton), we get $\theta=25$ degrees for $600 \mathrm{~Hz}$ and $\theta=39^{\circ}$ for $900 \mathrm{~Hz}$. This is right in the adiabatic regime, so our physical scenario would seem to make sense.

We now want to find the angular width of a peak in the adiabatic regime. Using a small angle approximation $\varphi \approx D / R_{l}$. Putting in an average number of $\theta=30^{\circ}$, and using $R_{l}=7 \mathrm{~km}$, the radius of the OMAS circular tracks in the experiment, we get $\varphi=3.27^{\circ}$, a good match to the angular regime of our data peaks.

Taking the frequency derivative of the adiabatic phase change criterion allows us to estimate how large broadband effects are in our experiment, i.e., the $200 \mathrm{~Hz}$ bandwidth used. Calculations show that the phase change is 0.22 radians over the band, i.e., $\Delta \theta \ll \pi$. Thus, our narrowband adiabatic result should be a reasonable approximation for looking at the broadband data.

\section{APPENDIX B: COUPLED MODE REGIME OF INTERNAL WAVE EFFECTS}

We will use the "resonance coupling condition" as our basic guide to what happens in the coupled mode azimuthal regime. Looking at Fig. 11(b), we see that this condition is:

$$
\Lambda_{I W}^{P R O J}=L / \sin \theta=\Delta_{m n}
$$

Typical mode cycle distances are 200 to $1000 \mathrm{~m}$, so for $L=200 \mathrm{~m}$, we get $\theta=11^{\circ}$ to $90^{\circ}$. This is again a reasonable angular range for considering mode coupling. To get the width of one of these coupling resonance peaks (or nulls), we can just slightly modify the mode cycle distance equation, i.e., use

$$
\Delta_{m n}=\frac{2 \pi}{\left(k_{m}-k_{n}\right) \pm \Delta k_{\mathrm{avg}}},
$$

where $\Delta k_{\mathrm{avg}}$ is the average spacing between normal modes. This criterion lets you know when you "slip off" the resonance onto the next (neighboring) one. We could use the exact spacing between modes for Eq. (B2), instead of the average, but the average keeps us in the "spirit of approximation" we have been employing. For a hard bottom waveguide, the number of modes is approximately

$$
n_{\text {modes }}=\frac{H}{\lambda / 2}=\frac{k H}{\pi} .
$$

Thus, the average mode spacing is

$$
\Delta k_{\mathrm{avg}}=\pi / H
$$

and then we obtain

$$
\Delta_{m n}=\frac{2 \pi}{\left(k_{m}-k_{n}\right) \pm \pi / H} .
$$

Using Eq. (B5) at $600 \mathrm{~Hz}$ gives a peak width of $10^{\circ}$, again in accord with our data. To look at this result in a broadband sense, we should consider: when would a change of frequency change the IW resonance condition from resonance between modes $m, n$ to modes $m, n \pm 1$ ? That is, again, our "slip by one mode" condition.

Without showing the details, our hard bottom waveguide approximation (above) was used with the experimental frequencies and bandwidth of the OMAS, and showed that the frequency effects caused a shift of $1 / 4$ the distance between the original modes. This means that our broadband coupling calculation is only "reasonably approximated" by the narrowband result, but could be improved.

\section{APPENDIX C: OMAS TESTING IN THE ABSENCE OF INTERNAL WAVES AND BOTTOM EFFECTS}

On April 21, 2008, an OMAS was deployed in the deep $(1350 \mathrm{~m})$ waters of the Tongue of the Ocean in the Bahamas, shown in the upper panel of Fig. 12. The source was 


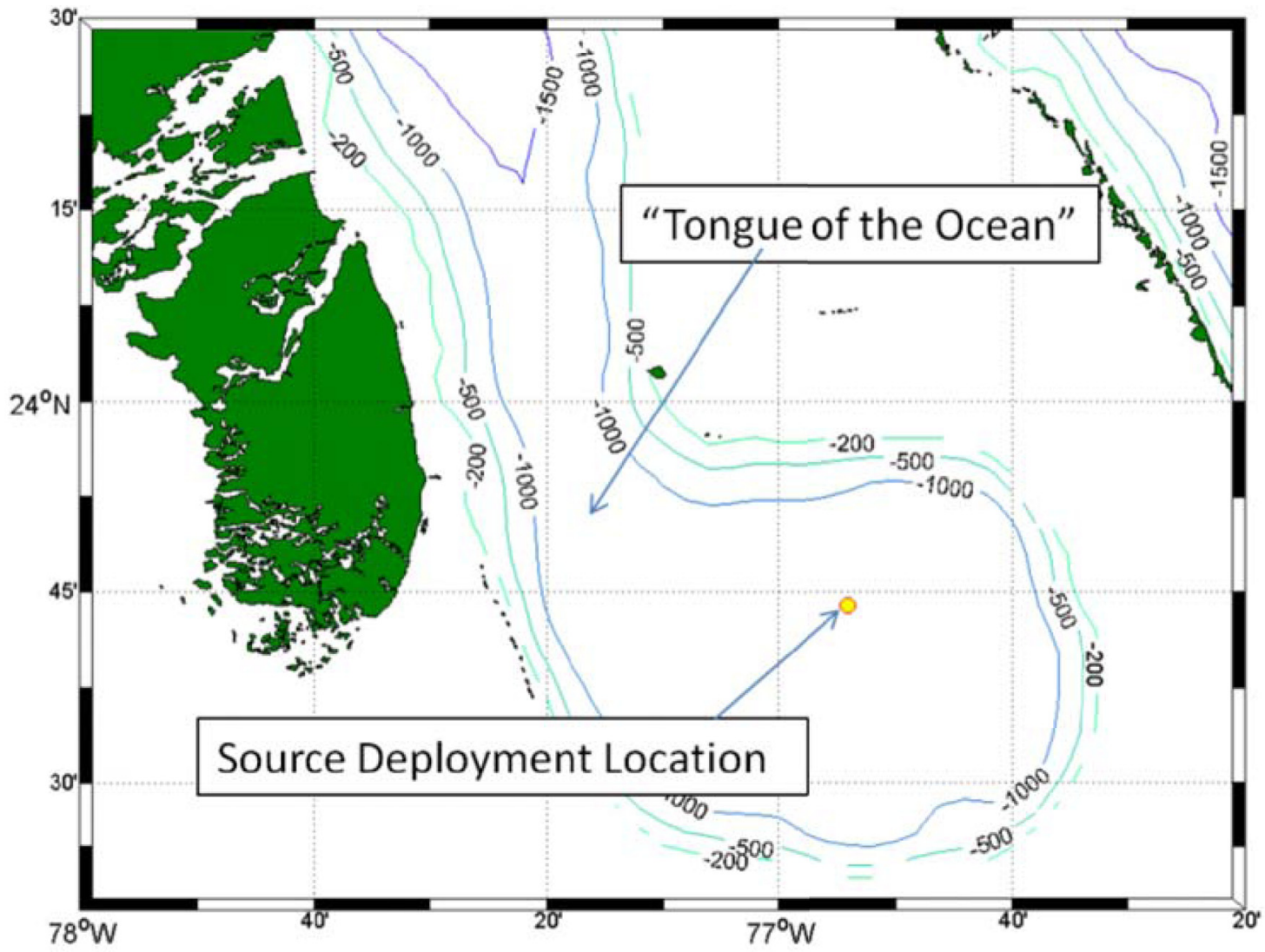

(a)

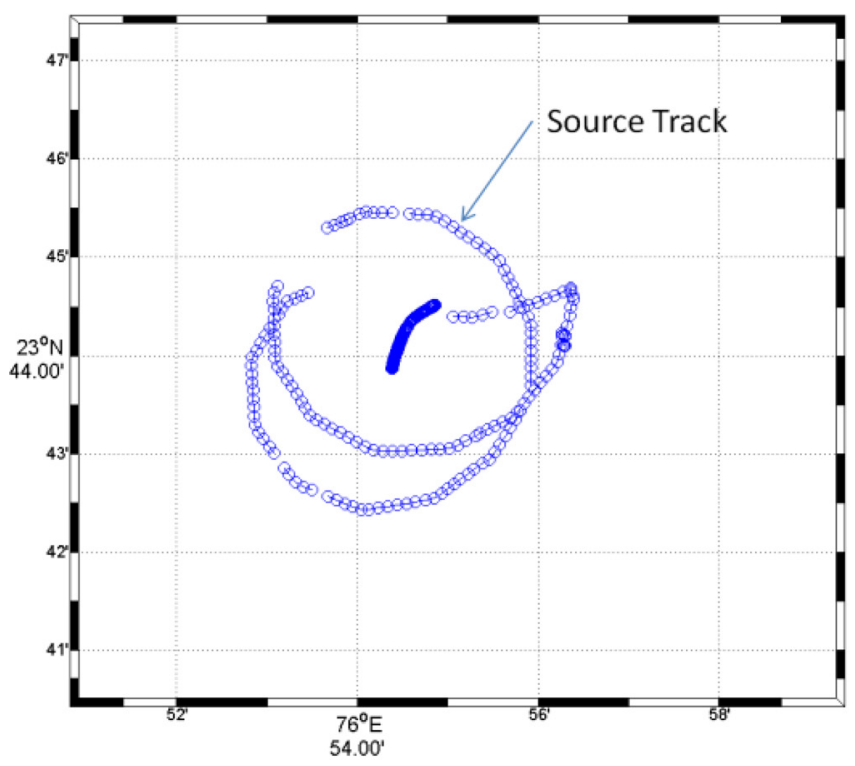

(b)

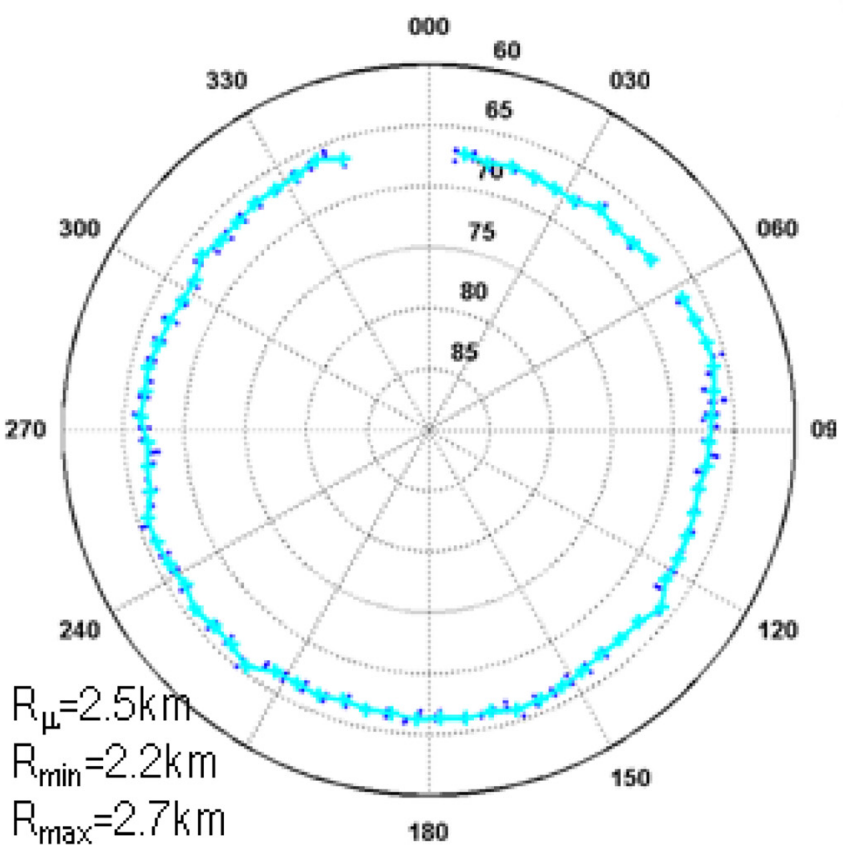

(c)

FIG. 12. (Color online) (a) OMAS deployment in the deep (1350 m) waters of the "Tongue of the Ocean" in the Bahamas on April 21, 2008. (b) OMAS Source Track, circle radius $\approx 2.5 \mathrm{~km}$. (c) Azimuthal TL variability, computed from the peak of the matched-filter output, measured by the OMAS operations on April 21, 2008. Individual TL data points are shown as dots. A $5^{\circ}$ bearing sector average is shown as a dotted line, with the points showing the mean value of all data within each sector plotted at the sector center point.

launched near $76^{\circ} 54^{\prime} \mathrm{W}, 23^{\circ} 44^{\prime} \mathrm{N}$, shown in Fig. 12 (a) as a circle, and performed two $2.5 \mathrm{~km}$ radius circles at a speed of five knots at a depth of $27 \mathrm{~m}$. The reconstructed source track can be seen in Fig. 12(b), with circles showing the source position and the thicker line showing the position of the sonobuoy used as a receiver for this test, also operating 
at a depth $27 \mathrm{~m}$. Similar to the OMAS1 in the data reported in this paper, the source transmitted three, two-second $800-1000 \mathrm{~Hz}$ HFM upsweeps every minute.

Individual TL data points, calculated as the difference between the known source level and the peak of the matched-filtered output for each transmission are rangecorrected to a $2.5 \mathrm{~km}$ common range using a $15 \log (\mathrm{R})$ correction and shown in Fig. 12(c) as dots. A $5^{\circ}$ bearing sector average is shown as a dotted line, with the plusses showing the mean value of all data within each sector plotted at the sector center point. The figure shows that the data are very isotropic, with only a $0.5 \mathrm{~dB}$ standard deviation to the mean points, and very repeatable, with only a $0.4 \mathrm{~dB}$ standard deviation to the set of the differences between the individual data points and the mean line.

Abbot, P., and Dyer, I. (2002). "Sonar Performance Predictions Incorporating Environmental Variability," in Impact of Littoral Environmental Variability on Acoustic Predictions and Sonar Performance, edited by N. G. Pace, and F. B. Jensen (Kluwer Academic Publications, The Netherlands), pp. 611-618.

Abbot, P., Gedney, C., Morton, D., and Emerson, C. (2006a). "Mobile acoustic source for underwater acoustic measurements," in Proc. IEEE/ MTS Oceans'06 Conference, Boston, MA, September 18-21, pp. 1-5.

Abbot, P., Dyer, I., and Emerson, C. (2006b). "Acoustic propagation uncertainty in the shallow East China Sea," IEEE J. Ocean. Eng. 21(2), 368-383.

Aikman, F., III. (1984). "Pycnocline development and its consequences in the Middle Atlantic bight," J. Geophys. Res. 89, pp. 685-694.

Badiey, M., Katznelson, B., Lynch, J., Pereselkov, S., and Siegmann, W. (2007). "Frequency dependence and intensity fluctuations due to shallow water internal waves," J. Acoust. Soc. Am. 122, pp. 747-760.

Ballard, M. S., Becker, K. M., and Goff, J. A. (2010). "Geoacoustic inversion for the New Jersey Shelf: 3-D sediment model,” IEEE J. Ocean. Eng. 35, 28-42.

Beers, Y. (1967). Introduction to the Theory of Error (Addison-Wesley, Reading, MA), pp. 1- 5 .

Boicourt, W. C., and Hacker, P. W. (1976). "Circulation on the Atlantic continental shelf of the United States, Cape May to Cape Hatteras," in Memoires de la Societe Royale des Sciences de Liege, edited by J. C. J. Nihoul (Univ. of Liege, Liege, Belgium), pp. 187-200.

Burrage, D. M., and Garvine, R. W. (1988). "Summertime hydrography at the shelfbreak front in the Middle Atlantic Bight," J. Phys. Oceanogr. 18, pp. 1309-1319.

Chuprov, S. D. (1982). "Interference structure of sound field in a layered ocean," in Akustikaokeana: Sovremennoe sostoyanie, edited by L. M. Brehovskikh (Nauka, Moscow), pp. 71-91.
Churchill, J. H., Manning, J. P., and Beardsley, R. C. (2003). "Slope water intrusions onto Georges Bank," J. Geophys. Res. 108, 8012.

Diachok, O. I., Smith, P., and Wales, S. (2004). "Classification of bioacoustic absorption lines at low frequencies: the Van Holiday connection," J. Acoust. Soc. Am. 115, 2521.

Diachok, O. I. (2005). "Bioacoustic absorption spectroscopy: a new approach to monitoring the number and lengths of fish in the ocean," in Sounds in the Sea, edited by H. Medwin and Colleagues (Cambridge University Press, Cambridge, UK), pp. 407.

Flagg, C. N., Houghton, R. W., and, Pietrafesa, L. J. (1994). "Summertime thermocline salinity maximum intrusions in the Mid-Atlantic Bight," Deep-Sea Res., Part II 41, pp. 325-340.

Gawarkiewicz, G., McCarthy, R. K., Barton, K., Masse, A. K., and Church, T. M. (1990). "A Gulf Stream-derived pycnocline intrusion on the Middle Atlantic Bight shelf," J. Geophys. Res. 95(22), 305-313.

Gawarkiewicz, G., Brink, K. H., Bahr, F., Beardsley, R. C., Caruso, M., Lynch, J. F., and Chiu, C.-S. (2004). "A large-amplitude meander of the shelfbreak front during summer south of New England: Observations from the Shelfbreak PRIMER experiment," J. Geophys. Res. 109, C03006.

Gordon, A., and Aikman F., III. (1981). "Salinity Maximum in the Pycnocline of the Middle Atlantic Bight," Limnol. Oceanogr. 26, $123-130$.

Harrison, C. H., and Harrison, J. A. (1995). "A simple relation between frequency and range averages for broadband sonar," J. Acoust. Soc. Am. 97, 1314-1317.

Houghton, R. W., Schlitz, R., Beardsley, R. C., Butman, B., and Chamberlin, J. L. (1982). "The Middle Atlantic bight cold pool: Evolution of the temperature structure during summer 1979," J. Phys. Oceanogr. 12, 1019-1029.

Linder, C. A., and Gawarkiewicz, G. (1998). "A climatology of the shelfbreak front in the Middle Atlantic Bight," J. Geophys. Res. 103, $18,405-18,423$.

Linder, C. A., Gawarkiewicz, G. G., and Taylor, M. (2006). "Climatological estimation of environmental uncertainty over the Middle Atlantic Bight shelf and slope," IEEE J. Ocean. Eng. 31, 308-324.

Makris, N. C., Ratilal, P., Symonds, D. T., Srinivasan, J., Lee, S., and Nero, R. W. (2006). "Fish population and behavior revealed by instantaneous continental shelf imaging," Science, 311, 660-663.

Oba, R., and Finette, S. (2002). "Acoustic propagation through anisotropic internal wave fields: Transmission loss, cross-range coherence, and horizontal refraction," J. Acoust. Soc. Am. 111, 769-784.

Tang, D. J., Moum, J. N., Lynch, J. F., Abbot, P., Chapman, R., Dahl, P. H., Duda, T. F., Gawarkiewicz, G. G., Glenn, S., Goff, J. A., Graber, H., Kemp, J., Maffei, A., Nash, J. D., and Newhall, A. E. (2007). "Shallow Water'06, A joint acoustic propagation/nonlinear internal wave physics experiment," Oceanography 20, 156-167.

Weinberg, H., and Burridge, R. (1974). "Horizontal ray theory for ocean acoustics," J. Acoust. Soc. Am. 55, 63-79.

Zhou, J., Zhang, X., and Rogers, P. H. (1991). "Resonant interaction of sound wave with internal solitons on coastal zone," J. Acoust. Soc. Am. 90, 2042-2054. 